\title{
Como o agente fiscalizador utiliza a comunicação online? A ideia de transparência pública nas redes sociais da Controladoria-Geral da União
}

\author{
Andressa Butture Kniess ${ }^{1}$ (iv \\ Francisco Paulo Jamil Marques ${ }^{2}$
}

\begin{abstract}
O artigo investiga se, e de que forma, a Controladoria-Geral da União (CGU) aborda a ideia de transparência em seus perfis de redes sociais. Três questões orientam a análise: Como o tema da transparência pública é mobilizado pela CGU no Facebook e no Twitter? Uma vez que Facebook e Twitter dispõem de estruturas e usuários distintos, que estratégias de comunicação são privilegiadas em cada rede? Em que medida as rotinas de comunicação digital da CGU foram transformadas na transição entre os governos Rousseff e Temer? A análise de conteúdo de 4.212 publicações no Facebook e no Twitter em 2015 e 2016 revelou que a instituição privilegia dois temas: transparência e corrupção. Ademais, autoridades públicas são pouco mencionadas, afastando-se uma perspectiva personalista de instrumentalização da comunicação. Descobriu-se, ainda, que a transição governamental efetivamente interferiu nas rotinas de publicação da entidade.
\end{abstract}

Palavras-chave: comunicação política; redes sociais digitais; transparência; comunicação pública; Controladoria-Geral da União

\section{Introdução}

"Todo cidadão tem direito de saber onde e como é gasto o dinheiro público. Exija \#transparência dos gastos!" (CGU, 9/2/2015)33. Esse é um tweet da Controladoria-Geral da União (CGU), principal órgão de combate à corrupção no âmbito do Poder Executivo Federal brasileiro e responsável por orientar e supervisionar as políticas de transparência. Porém, se a arquitetura institucional brasileira prevê que a CGU fiscalize outras instituições e demande transparência a elas, de que forma tal entidade aborda a ideia de transparência pública em suas próprias redes sociais?

\footnotetext{
1 Universidade Federal do Paraná. Programa de Pós-Graduação em Ciência Política. Curitiba (PR), Brasil. Bolsista Capes. Integrante do Grupo de Pesquisa em Comunicação, Política e Tecnologia (PONTE). E-mail: <andressakniess@gmail.com>.

2 Universidade Federal do Paraná. Programa de Pós-Graduação em Ciência Política. Curitiba (PR), Brasil. Bolsista de Produtividade em Pesquisa do CNPq (PQ-2). Coordenador do Grupo de Pesquisa em Comunicação, Política e Tecnologia (PONTE). E-mail: <marquesjamil@gmail.com>.

${ }^{3}$ Disponível em: <https://twitter.com/CGUonline/status/564726748089425920>. Acesso em: 24 fev. 2020.
} 
A crescente adoção das redes sociais digitais por parte de um contingente cada vez mais numeroso de cidadãos fez com que governos de todo o mundo passassem a utilizar tais plataformas com o intuito de incrementar os processos relacionados à transparência pública (Ruijer et al., 2020; Hansen e Flyverbom, 2015; Gomes, Amorim e Almada, 2018; Guillamón et al., 2016; Margetts, 2011; Bertot, Jaeger e Grimes, 2010; Braga, 2007; Pina, Torres e Royo, 2007). Por meio desses canais, as instituições do Estado são capazes não somente de atingir maiores parcelas da população, mas também de construir imagens e identidades institucionais que Ihes são favoráveis (DePaula e Dincelli, 2018; Bauhr e Grimes, 2014; Miola e Marques, 2020; Marques et al., 2019).

Considerando que a comunicação digital tem exercido um papel relevante no que concerne ao aprimoramento da publicidade de Estado e de governo, o objetivo deste artigo é investigar se, e de que forma, a CGU aborda a ideia de transparência pública por meio de seus perfis em redes sociais digitais.

Para isso, propõe-se uma análise de conteúdo quanti-qualitativa de todas as 4.212 postagens da CGU publicadas no Facebook $(n=1.181)$ e no Twitter $(n=3.031)$ ao longo de 2015 e 2016. Os posts de $1^{\circ}$ de janeiro de 2015 a 11 de maio de 2016 se referem ao período em que Dilma Rousseff esteve à frente do governo. Já as publicações de 12 de maio de 2016 a 31 de dezembro de 2016 compreendem o material veiculado durante o governo de Michel Temer.

O recorte se justifica não somente por consistir em um intervalo temporal representativo, mas também porque permite examinar de que forma dois eventos políticos ocorridos à época influenciaram as políticas de transparência no Brasil, a saber: o impeachment da então presidente Dilma Rousseff (PT), em maio de 2016, que levou Michel Temer (MDB) à presidência da República; e o fato de Temer ter assinado a Medida Provisória (MP) 726/2016 (Brasil, 2016a) logo após ter assumido. Por meio dessa MP, Temer extinguiu a Controladoria-Geral da União (CGU) e a substituiu pelo Ministério de Transparência, Fiscalização e Controle (MTFC). A CGU, criada em 2003, tinha como função dar assistência direta e imediata ao presidente da República em assuntos relativos à transparência e ao combate à corrupção. A MP 726/16 estabeleceu que o MTFC deveria assumir as funções da antiga CGU, mas o desvinculou da presidência da República e o tornou hierarquicamente igual aos demais ministérios - o que deu origem a protestos por parte de autoridades e servidores ${ }^{4}$. Fabiano Angélico, especialista na área de transparência governamental, afirmou, à época, que o ideal seria contar com um órgão controlador acima dos controlados - caso contrário, as recomendações tornar-se-iam apenas sugestões 5 . Quando a MP 726/16 foi convertida na Lei n¹3.341 (Brasil, 2016b), a nomenclatura da

\footnotetext{
4 Ver em: <http://g1.globo.com/politica/noticia/2016/05/servidores-da-cgu-protestam-por-saida-doministro-fabiano-silveira.html>. Acesso em: 2 set. 2019.

5 Ver em: <https://gauchazh.clicrbs.com.br/politica/noticia/2016/05/para-especialistas-fim-da-cguenfraquece-controle-e-combate-a-corrupcao-no-pais-5801064.html>. Acesso em: 2 set. 2019.
} 
instituição foi novamente modificada: o órgão tornou-se o Ministério da Transparência, Fiscalização e Controladoria-Geral da União - retomando-se a tradicional sigla, CGU6.

Argumenta-se que o artigo é relevante tanto porque é uma oportunidade de atualizar a literatura na área de e-transparência quanto porque o caso selecionado envolve o estudo de um órgão da estrutura do Estado brasileiro que tem sido alvo de pressões políticas. Além disso, se boa parte da literatura nacional sobre transparência pública tem se concentrado em investigar websites de governo (Ferracioli e Herman, 2019; Schlindwein, 2019; Angeli, 2017; Almada, 2016; Amorim, 2012; Hoch, Rigui e Silva, 2012), pouco se sabe acerca de como as instituições brasileiras empregam as redes sociais digitais a fim de abordar a ideia de transparência junto a seus seguidores.

Destaca-se, ademais, que este manuscrito se mostra atento ao fato de que as redes sociais digitais possuem diferentes gramáticas. Isto é, mesmo que tais plataformas permitam que os usuários criem ou compartilhem conteúdos a partir de seus próprios perfis, é fundamental refletir sobre a maneira pela qual funcionalidades que caracterizam cada rede social interferem nas experiências dos usuários - o que evita uma perspectiva meramente instrumental quando da análise dos conteúdos publicados.

Este artigo está dividido em quatro partes. A seção "Revisão de literatura" discute de que maneira as redes sociais digitais têm sido utilizadas para promover a transparência pública em experiências de alcances diversos. Posteriormente, em "Questões de pesquisa e estratégias metodológicas", são esclarecidas as técnicas de coleta e de análise de dados. A seção "Resultados" divide-se em três subseções: "Estatísticas descritivas", "Padrões de publicação da CGU no Facebook e no Twitter" e "Padrões de publicação da CGU durante os governos de Dilma Rousseff e Michel Temer". A seção "Discussão dos resultados e conclusões", voltada para discutir as descobertas à luz da literatura pertinente, encerra o manuscrito.

\section{Revisão de literatura}

Transparência pública digital

Ainda que o conceito de publicidade seja discutido desde antes de uma maior adoção dos regimes democráticos em países do Ocidente (Bentham, 2011; Filgueiras, 2011; Bodei, 2011; Kant, 2008; Hood, 2006), foi apenas a partir do século XX que o tema da transparência pública ganhou maior expressão na literatura (Etzioni, 2018; Marques, 2016a; Piotrowski, 2008).

Apesar das controvérsias conceituais existentes entre os estudiosos contemporâneos, um argumento relativamente consensual se refere à ideia de que a transparência não se resume à simples oferta de dados (Grimmelikhuijsen, Porumbescu e Hong, 2013; Pinho e Sacramento, 2009). Em outras palavras, a natureza da informação

\footnotetext{
${ }^{6}$ A Lei no 13.844 (Brasil, 2019) retomou a nomenclatura - Controladoria-Geral da União.
} 
tornada disponível e a conveniência franqueada aos cidadãos para que utilizem tais dados com vistas a fortalecer o controle social da coisa pública passam a ser questões pertinentes ao debate sobre transparência (Cucciniello, Porumbescu e Grimmelikhuijsen, 2016).

De acordo com Fung (2013), são quatro os princípios que caracterizam a eficácia das políticas de transparência pública: 1) disponibilidade das informações aos cidadãos; 2) proporcionalidade (dados diretamente associados à vida cotidiana dos cidadãos necessitam de atenção especial); 3) acessibilidade (i.e., conveniência de acesso e compreensibilidade dos dados); e 4) capacidade de ação (o que permite à esfera da cidadania atuar - seja fiscalizando, seja punindo instituições e agentes públicos).

Contudo, ainda que a transparência seja essencial aos regimes democráticos, a literatura também faz ressalvas a tal princípio. Uma das preocupações se refere à utilização de mecanismos de transparência para a construção de imagens públicas de caráter personalista - o que ocorre quando atores políticos instrumentalizam tais recursos mais para consolidar uma boa imagem de si do que para aumentar o controle sobre a coisa pública (Urbinati, 2013; Dror, 1999). Outra questão pertinente se refere ao "dilema do lado da oferta" (Angélico, 2016), segundo o qual se identifica uma contradição entre visibilidade e "inferabilidade" dos dados. Isto é, nem todos os cidadãos compreendem os dados disponíveis, mas um processo de "tradução" das informações pode implicar a inserção de vieses cujo objetivo é atender a interesses particulares de determinado ator.

Tais problemas, entretanto, não minam a expectativa de que os media digitais possam aprimorar a comunicação entre instituições públicas e cidadãos, ampliando a efetividade dos mecanismos de transparência. Entre as oportunidades destacadas pela literatura estão baixo custo (Picazo-Vela, Gutiérrez-Martínez e Luna-Reyes, 2012; Roberts, 2006), linguagem mais acessível (Porumbescu, 2017) e possibilidade de convocar os cidadãos à participação política por meio de atividades de fiscalização (Bertot, Jaeger e Grimes, 2010; Graham, 2014).

De fato, estudiosos da área têm investido em diferentes estratégias metodológicas para investigar se, e de que forma, as plataformas digitais contribuem com a promoção da transparência pública (Guillamón et al., 2016; Lourenço, 2015; Graham, 2014). Entre esses trabalhos, está o de Stamati, Papadopoulos e Anagnostopoulos (2015), que enumera cinco oportunidades destacadas por executivos responsáveis por iniciativas de transparência digital na Grécia: 1) formação de uma linguagem comum a agentes públicos e cidadãos; 2) visibilidade das ações de Estado e de governo; 3) oportunidades para que os cidadãos participem da produção de conteúdo; e 4) incentivo à expressão de opiniões por conta da promessa de anonimato. Mergel (2013), por sua vez, enfatiza o relato de gestores que trabalham para o governo norte-americano, segundo os quais as instituições de Estado devem estar onde o público está - e as redes sociais podem atrair cidadãos que não costumam interagir de forma rotineira com a administração pública.

Guillamón et al. (2016), bem como Bonsón et al. (2012), estudam de que modo instituições públicas utilizam as redes sociais digitais para promover transparência. Os resultados indicam que determinados municípios da União Europeia empregam tais 
plataformas para ampliar a prestação de contas, mas pouco interagem com os cidadãos através delas (Bonsón et al., 2012); e que, no caso de governos locais italianos e espanhóis, gestores de esquerda e de direita divulgam uma quantidade semelhante de informações (Guillamón et al., 2016).

Outra vertente de investigações busca compreender a opinião dos cidadãos acerca de políticas de transparência. Através de um survey aplicado junto a usuários de Twitter da Coreia do Sul, Kim, Park e Rho (2015) demonstram que as ações de transparência no referido microblog têm efeito positivo sobre a confiança no governo. Em contrapartida, no caso dos cidadãos de Omã, os entrevistados não costumam associar o uso das redes sociais digitais ao incremento dos mecanismos de transparência pública (Al-Aufi et al., 2017). Porumbescu (2017), por sua vez, examina o grau de confiança que a população de Seul (Coreia do Sul) deposita em agentes públicos ao utilizar como variável as ferramentas de transparência pública digital disponíveis. O autor conclui que a presença do governo em redes sociais digitais melhora - de forma mais efetiva do que conseguem os websites - as percepções dos cidadãos a respeito de competência e honestidade no âmbito da administração pública. Os resultados, porém, contradizem aqueles encontrados em governos locais do México (Valle-Cruz, Sandoval-Almazan e Gil-Garcia, 2016): no referido país, tecnologias de comunicação digital mais tradicionais (como websites) têm um efeito mais significativo e positivo sobre a percepção do público a respeito da transparência e da eficiência governamentais do que as redes sociais digitais.

Tal variedade de resultados acerca das impressões que os cidadãos têm quanto ao uso político dos media digitais reforça a noção de que políticas de transparência propostas em contextos sociais diferentes tendem a provocar efeitos diversos (Cucciniello, Porumbescu e Grimmelikhuijsen, 2016). Bertot, Jaeger e Grimes (2012) defendem, mais exatamente, que a efetividade das ferramentas online está diretamente relacionada ao ambiente político, cultural e legal de cada país.

Não obstante a quantidade crescente de investigações que associam redes sociais digitais e transparência pública, ainda se verifica uma lacuna na literatura a respeito de como instituições do Estado - especificamente as responsáveis por fiscalizar gastos públicos e conduzir políticas de transparência - utilizam as redes sociais para abordar a ideia de transparência. Em outras palavras, além de averiguar em que medida os órgãos públicos estão presentes nas redes sociais, é necessário diagnosticar os temas mais recorrentemente abordados e as estratégias de comunicação utilizadas para atrair a atenção dos usuários.

\section{Estruturas e gramáticas de comunicação que caracterizam Twitter e Facebook}

As redes sociais digitais podem ser definidas como um conjunto de aplicativos que facilitam a criação e o compartilhamento de conteúdos e que funcionam através de diversos dispositivos, como computadores, tablets e celulares (Davis, 2015; Ellison e Boyd, 2013). Entretanto, cada uma dessas plataformas possui seus próprios recursos, estruturas, 
funcionalidades e base de usuários - o que significa que as configurações de tais ferramentas se refletem diretamente nos meios e modos como seus usuários as utilizam (Bossetta, 2018; Luna-Reyes, 2017; Ernst et al., 2017).

Bossetta (2018) enumera quatro elementos que marcam a especificidade de cada rede social: estruturas da rede (a forma como ocorrem as conexões entre os usuários), funcionalidades (dispositivos pelos quais a rede social é acessada e a sua interface gráfica), algoritmos (elementos que definem a seleção, a sequência e a visibilidade dos conteúdos) e datafication ("rastros digitais" deixados pelos usuários nessas plataformas e que podem ser coletados e utilizados para publicidade, pesquisas de mercado, refinamento de algoritmos etc.).

Luna-Reyes (2017), por sua vez, afirma que as empresas responsáveis por configurar e gerenciar as redes sociais digitais buscam monetizar as atividades de seus usuários. Portanto, não se pode descartar o fato de que as interações ocorridas nesses sites (mesmo no caso de debates de interesse público) são mediadas por algoritmos que agenciam determinadas potencialidades comunicativas mais do que outras.

No Brasil, Facebook e Twitter diferem substancialmente em número de usuários. De acordo com levantamento da Cuponation, há 130 milhões de brasileiros utilizando o Facebook ${ }^{7}$. No caso do Twitter, o país conta com algo em torno de 8 milhões de usuários ativos $^{8}$. Outra diferença entre as duas redes sociais digitais - dessa vez, relativa à funcionalidade - está na quantidade máxima de caracteres permitida em cada postagem. Enquanto no Facebook não há restrições de espaço, o Twitter limita cada post a, no máximo, 280 caracteres. Até novembro de 2017 (durante o recorte temporal deste artigo, portanto), as postagens eram ainda menores (limitadas a 140 caracteres).

Outra distinção importante é concernente ao tipo de usuário de cada rede social. Em entrevista concedida a Sodré (2014), um dos gestores responsáveis pelas redes sociais da CGU reconhece que as duas plataformas compreendem públicos distintos e que, por isso, as estratégias de comunicação a serem empregadas em cada uma devem ser diferentes. Ou seja, pelo menos no âmbito do órgão em questão, as postagens do Facebook tendem a tratar de assuntos mais próximos do dia a dia dos cidadãos, enquanto temas de natureza técnica são preferencialmente divulgados no Twitter:

(...) inicialmente a gente trabalhava com os mesmos conteúdos para todas as redes, obviamente pro Youtube não, e aí você tinha uma notícia que repercutia tanto no Facebook quanto no Twitter, hoje em dia a gente já chegou numa maturidade que a gente vê "não, isso aqui não tem cara de Facebook", hoje mesmo a gente teve um caso, a CGU faz um trabalho muito técnico de análise das contas da União, no Facebook isso não tem muita atratividade, não da forma que o trabalho da CGU acontece, então a gente só colocou no Twitter,

\footnotetext{
${ }^{7}$ Ver em: <https://www.cuponation.com.br/insights/facebook-users>. Acesso em: 2 out. 2019.

8 Ver em: <https://www.tecmundo.com.br/redes-sociais/144654-brasil-10-paises-usuarios-twitter.htm>. Acesso em: 2 out. 2019.
} 
então assuntos mais técnicos, às vezes para um público mais de jornalistas, a gente foca mais no Twitter, apesar da gente também colocar alguns conteúdos em ambas as redes. Objetivo? Sim, acho que o objetivo é muito próximo, mas o público e o conteúdo divulgado têm as suas peculiaridades, a gente respeita as peculiaridades de cada rede (...) (Sodré, 2014, p. 160).

Em consonância com tal estratégia revelada pelos administradores dos perfis da Controladoria-Geral da União, Ernst e colegas (2017) apontam que, em perfis de partidos políticos, mensagens de caráter "populista" aparecem com mais frequência no Facebook do que no Twitter. De acordo com os autores, "Facebook's advantages include higher levels of proximity and reciprocity, unlimited space for messages, and its non-elite character" ( $p$. 12). Tal conclusão desperta a necessidade de investigar em que medida a base de usuários do Twitter poderia compreender um público mais especializado do que aquele que costuma utilizar o Facebook.

\section{Questões de pesquisa e estratégias metodológicas}

Diante da discussão conceitual proposta até aqui, este artigo apresenta três questões de pesquisa:

RQ1: Com que frequência - e de que forma - o tema da transparência pública é mobilizado pela CGU em seus perfis no Facebook e no Twitter?

RQ2: Considerando-se que Facebook e Twitter dispõem de estruturas distintas e contingentes de usuários nem sempre coincidentes, quais estratégias de comunicação a CGU privilegia nas duas redes sociais?

RQ3: Em que medida as rotinas de comunicação da CGU em redes sociais foram transformadas a partir da transição entre os governos de Dilma Rousseff e Michel Temer?

A fim de endereçar tais indagações, o artigo analisa todas as postagens da CGU publicadas ao longo de 24 meses - mais precisamente, entre janeiro de 2015 e dezembro de 2016. Durante tal período, a instituição publicou 3.031 tweets e 1.181 posts no Facebook. No caso do Facebook, a coleta de dados ocorreu através do aplicativo Netvizz, em setembro de 2017. Já as postagens do Twitter foram coletadas manualmente, em abril de 2018.

A estratégia metodológica utilizada no artigo é a análise de conteúdo ( $A C)$, envolvendo um conjunto de técnicas já regularmente empregadas no campo da comunicação política (Skalski et al., 2017; Neuendorf e Kumar, 2015; Bardin, 1977). A partir da pré-análise do corpus (Bardin, 1977), e também se fundamentando em outros trabalhos que propõem categorias para analisar as postagens de instituições públicas em redes sociais digitais (DePaula e Dincelli, 2018; Sodré, 2014; Gunawong, 2014), foi elaborado um livro de códigos específico para lidar com o objeto selecionado para estudo.

A elaboração das categorias foi resultado de um debate realizado por pesquisadores previamente treinados para a utilização de técnicas de AC. Após uma leitura 
preliminar das postagens, e com o intuito de evitar sobreposição de categorias, as variáveis foram examinadas uma a uma visando alcançar resultados mais consistentes.

O Quadro 1 apresenta as seis variáveis categóricas que constituem o livro de códigos. Ressalta-se que quatro delas são dummy (ou seja, são binárias) e indicam presença ou ausência de determinado elemento. As outras duas variáveis "Direcionamento do link" e "Tema da postagem" - dividem-se em quatro e dez subcategorias, respectivamente:

\section{Quadro 1}

\section{Variáveis que integram o livro de códigos}

1) Presença de link: Indica se a postagem apresenta link que direciona o usuário a um conteúdo externo. Esse item não observa o conteúdo do link, apenas registra sua presença ou ausência.

2) Direcionamento do link: Quando há presença de link na postagem, o conteúdo do link é classificado em uma das seguintes categorias:

a) Portais relacionados à CGU: Site oficial e redes sociais do órgão, Portal da Transparência e Portalzinho da CGU.

b) Outros sites ou páginas governamentais: Demais sites ou páginas de redes sociais relativos aos três poderes e aos três níveis da federação.

c) Demais sites: Todos os outros sites ou páginas.

d) Link não identificável: Links não identificáveis por estarem indisponíveis.

3) Apelo ao envolvimento dos usuários: Indica se o post convida os usuários à participação política. Marca-se presença quando o usuário é convocado a acessar conteúdos, engajar-se em uma campanha, acionar a Lei de Acesso à Informação (LAI), exercer controle social, fiscalizar contas e ações públicas, denunciar irregularidades ou fazer comentários nas postagens.

4) Menção à legislação: Indica se a publicação menciona uma legislação específica. É necessário que o post especifique a qual dispositivo legal está se referindo.

5) Menção à personalidade ou autoridade: Indica se a postagem cita nomes de representantes políticos ou personalidades da sociedade civil (lideranças sociais, intelectuais, cientistas, artistas etc.).

6) Tema da postagem: Indica o assunto predominante no texto da publicação. Cada publicação foi classificada em apenas uma das dez categorias abaixo:

a) Agenda e atribuições da CGU: O conteúdo trata das atribuições da CGU, menciona eventos dos quais o órgão participa, bem como contempla entrevistas concedidas por seus integrantes.

b) Cursos e concursos: Posts que tratam de cursos (promovidos ou não pela CGU), capacitações sobre controle social e concursos (de desenho, redação, curta-metragem etc.) que abordam temas relativos à instituição.

c) Corrupção e demais irregularidades: Publicações em que a questão da corrupção é predominante: investigações das quais a CGU participa, medidas contra a corrupção, exemplos sobre atos de corrupção praticados no dia a dia, notícias sobre punição a servidores públicos ou a pessoas investigadas por fraudes.

d) Transparência: Postagens nas quais o tema da transparência é predominante. Podem tratar de sites, aplicativos, cartilhas e legislações que visam reforçar ações de transparência, controle social, dados abertos, governo aberto ou índices de transparência.

e) Gestão pública: Conteúdos que se referem a regras da administração pública ou que tratam de fiscalizações de programas ou serviços públicos. 
f) Participação: Postagens que discorrem sobre participação política dos cidadãos ou atuação deles em ouvidorias, conselhos municipais, consultas públicas, denúncias, manifestações ou sugestões. Não necessariamente existe convite à participação do usuário, mas, sim, a menção ao tema.

g) Pensamentos: Posts com frases sobre ética, atitudes vinculadas ao combate à corrupção e à boa governança.

h) Feriados e datas comemorativas: Conteúdos relativos a feriados ou datas comemorativas. Podem discorrer sobre o aniversário de cidades brasileiras, Dia da Mulher ou outras ocasiões festivas de importância social e cultural.

i) Programas de civilidade e ética: Publicações que tratam de programas ou projetos educativos sobre ética, cidadania e demais valores cívicos.

j) Outros: Postagens que não se enquadram nos itens anteriores.

Fonte: Elaboração própria.

A fim de ampliar a confiabilidade do estudo, a classificação do corpus se submeteu a um teste de estabilidade, conforme sugerido por Krippendorff (2004). Nesse caso, depois de obedecer a um intervalo de tempo após a primeira categorização, um mesmo codificador realiza um novo procedimento classificatório, empregando as mesmas categorias de análise. Desse modo, passados três meses após a primeira codificação, foram selecionados 100 posts, de forma aleatória, para serem classificados novamente. Em todas as variáveis, a concordância ficou acima de $87 \%$.

Os resultados que constam no tópico a seguir são apresentados e interpretados através de estatística descritiva, testes de associação entre variáveis (qui-quadrado e $\mathrm{V}$ de Cramér) e resíduos padronizados (RP). O qui-quadrado é empregado para confirmar ou refutar uma hipótese de dependência entre duas variáveis categóricas (ou seja, para saber se essas variáveis estão ou não associadas entre si). Quando o qui-quadrado mostra a existência de associação entre as variáveis, o teste $V$ de Cramér é utilizado para diagnosticar a intensidade dessa associação. Empregado apenas para variáveis nominais, o $V$ de Cramér varia entre 0 e 1 e, quanto mais próximo de 1 , mais alto é o grau de associação. Por fim, são apresentados os resíduos padronizados, que servem para verificar a diferença entre os valores observados e os valores esperados de uma determinada distribuição (Field, 2005). Com o intervalo de confiança de 95\%, consideram-se significativos os valores acima de 1,96 e abaixo de $-1,96$.

Ainda do ponto de vista dos procedimentos metodológicos, é válido sublinhar que os dados relativos a eventuais alterações na equipe responsável pela gestão das redes sociais da CGU foram coletados por meio de solicitação formal, encaminhada através da Lei de Acesso à Informação (ver Figuras 1 e 2 do Documento Suplementar).

\section{Resultados}

Os resultados são apresentados em três etapas: na primeira parte, constam as estatísticas descritivas de todas as variáveis que integram o livro de códigos. Na segunda 
e terceira subseções são apresentados os padrões de publicação da CGU no Facebook e no Twitter e os padrões de publicação da CGU durante os governos de Dilma Rousseff e Michel Temer.

Destaque-se que a apresentação dos dados quantitativos é complementada com a discussão de postagens publicadas nos perfis aqui examinados a fim de aprofundar uma abordagem qualitativa crítica acerca dos padrões e estratégias de comunicação empregadas pela Controladoria-Geral da União. Ademais, esta seção se concentra na exposição dos dados de natureza quantitativa e qualitativa, deixando a discussão e as críticas às formas de uso para a seção seguinte.

\section{Estatísticas descritivas}

A Tabela 1 apresenta as frequências descritivas das variáveis "Presença de link", "Apelo ao envolvimento dos usuários", "Menção à legislação" e "Menção à personalidade ou autoridade":

Tabela 1

Estratégias de comunicação adotadas pela CGU no Facebook e no Twitter - N (\%)

\begin{tabular}{|l|c|c|c|}
\hline & Presença & Ausência & Total \\
\hline Presença de link & $2.875(68,3)$ & $1.337(31,7)$ & $4.212(100)$ \\
\hline Apelo ao envolvimento dos usuários & $2.616(62,1)$ & $1.596(37,9)$ & $4.212(100)$ \\
\hline Menção à legislação & $890(21,1)$ & $3.322(78,9)$ & $4.212(100)$ \\
\hline Menção à personalidade ou autoridade & $317(7,5)$ & $3.895(92,5)$ & $4.212(100)$ \\
\hline
\end{tabular}

Fonte: Elaboração própria com base nas postagens da CGU.

Nota-se que, em mais da metade dos posts, a CGU divulga links externos e apela para o envolvimento dos usuários. A "Presença de links" nas publicações, assim, é a estratégia de comunicação mais utilizada pela instituição, ocorrendo em $68,3 \%$ das postagens (2.875).

Os sites relacionados à CGU são os mais divulgados, correspondendo a 75,6\% dos links classificados. Esses links levam os usuários ao próprio site oficial da $\mathrm{CGU}^{9}$, ao Portalzinho da CGU, às redes sociais do órgão ou ao Portal da Transparência ${ }^{10}$. Em segundo lugar, ficam os demais sites governamentais, que equivalem a $12,8 \%$ dos links veiculados. Entre os mais divulgados, estão o Portal de Ouvidoria do Governo Federal ${ }^{11}$ e o site da Escola Nacional de Administração Pública ${ }^{12}$ (visto que a Enap oferece cursos e capacitações que tratam de transparência e acesso à informação). Já os links classificados como

\footnotetext{
${ }^{9}$ Ver em: <https://www.gov.br/cgu/pt-br>. Acesso em: 8 set. 2020.

10 Ver em: <http://www.portaltransparencia.gov.br/>. Acesso em: 8 set. 2020.

${ }_{11}$ Ver em: <https://www.gov.br/ouvidorias/pt-br>. Acesso em: 8 set. 2020.

12 Ver em: <https://www.enap.gov.br/pt/>. Acesso em: 8 set. 2020.
} 
"Outros" (que correspondem a 12,5\%) direcionam o usuário, na maioria das vezes, a sites de instituições jornalísticas. A organização não governamental "Artigo 19" - que promove o direito à liberdade de expressão e ao acesso à informação ${ }^{13}$ - também é recorrentemente divulgada pela entidade aqui analisada ${ }^{14}$.

O "Apelo ao envolvimento dos usuários" (quando a postagem convida o usuário a acessar conteúdos, comentar ou compartilhar publicações ou denunciar irregularidades) ocorre em $62,1 \%$ dos posts (2.616). Seguem dois exemplos:

Você tem reclamações, elogios ou dúvidas referentes a serviços e agentes públicos federais? Fale com a \#CGU http://goo.gl/qEMaJj (Twitter $2 / 1 / 2015)^{15}$.

Acesse os relatórios completos da Lei de Acesso sobre os pedidos de informação realizados ao Governo Federal. \#LAI http://goo.gl/KVwZZ7 (Twitter - 13/7/2015) $)^{16}$.

Em 21,1\% do corpus (890 postagens), a CGU menciona alguma legislação específica. A Lei de Acesso à Informação é a norma mais citada, estando presente em 593 posts. Muitas dessas postagens não apenas mencionam a lei, mas também oferecem instruções aos usuários sobre como utilizá-la para fortalecer o controle social da coisa pública:

A \#LeideAcessoàInformação (LAI) é uma ferramenta essencial para o incremento da transparência pública e consequentemente para a prevenção e o combate à corrupção. A LAI é válida para o Legislativo, Executivo e Judiciário, nas três esferas de poder (federal, estadual e municipal). Saiba mais sobre o acesso à informação pública com a cartilha da CGU e exerça sua cidadania! http://goo.gl/8nvEO9 (Facebook - 12/3/2015) ${ }^{17}$.

A Lei Anticorrupção, no 12.846 (Brasil, 2013), por sua vez, é mencionada em 76 publicações. A referida norma dispõe sobre a responsabilização de pessoas jurídicas por práticas de corrupção relacionadas à administração pública. Assim como acontece em postagens que tratam da LAI, a CGU relata ao usuário pontos cruciais da legislação:

\#LeiAnticorrupcao: A multa a empresas que cometeram atos lesivos deve ser recolhida em até 30 dias. Saiba mais em http://www.cgu.gov.br (Twitter $7 / 5 / 2015)^{18}$.

\footnotetext{
13 Ver em: <http://artigo19.org/>. Acesso em: 8 set. 2020.

14 Ver Tabela 1 do documento suplementar.

15 Ver em: <https://twitter.com/CGUonline/status/550955963558395904>. Acesso em: 7 set. 2020.

${ }^{16}$ Ver em: <https://twitter.com/CGUonline/status/620601717969801216>. Acesso em: 7 set. 2020.

17 Ver em:

<https://www.facebook.com/cguonline/photos/a.379439358766803.92592.171477772896297/913921985

318535/?type $=3>$. Acesso em: 7 set. 2020.

18 Ver em: <https://twitter.com/CGUonline/status/596296158974185472>. Acesso em: 7 set. 2020.
} 
Verificou-se que, dentre as estratégias de comunicação apresentadas na Tabela 1, a "Menção à personalidade ou autoridade" foi a menos utilizada pela CGU. Apenas 7,5\% das postagens (317) mencionam algum ator político ou personalidade da sociedade civil. No caso, ex-ministros da CGU - Valdir Simão, Carlos Higino, Luiz Navarro, Torquato Jardim e Fabiano Silveira - são mais recorrentemente citados. Apenas cinco publicações citam a ex-presidente Dilma Rousseff e duas mencionam seu sucessor - Michel Temer. Das cinco postagens que se endereçam a Rousseff, quatro abordam o tema da corrupção e uma trata da transmissão do cargo de ministro da CGU, de Jorge Hage Sobrinho para Valdir Simão, em janeiro de 2015. Temer é mencionado também em um post sobre troca de ministros e em uma publicação que explica a mudança organizacional de Controladoria-Geral da União para Ministério da Transparência, Fiscalização e Controle.

Apresentados os resultados das variáveis dummy, inicia-se a exposição das estatísticas descritivas atinentes aos temas das postagens (Tabela 2):

Tabela 2

Temas das postagens da CGU no Facebook e no Twitter

\begin{tabular}{|l|c|}
\hline Tema da postagem & N (\%) \\
\hline Transparência & $1.145(27,2)$ \\
\hline Corrupção e demais irregularidades & $1.032(24,5)$ \\
\hline Participação & $396(9,4)$ \\
\hline Agenda e atribuições da CGU & $375(8,9)$ \\
\hline Cursos e concursos & $315(7,5)$ \\
\hline Gestão pública & $298(7,1)$ \\
\hline Pensamentos & $230(5,5)$ \\
\hline Feriados e datas comemorativas & $166(3,9)$ \\
\hline Outros & $136(3,2)$ \\
\hline Programas de civilidade e ética & $119(2,8)$ \\
\hline Total & $4.212(100)$ \\
\hline
\end{tabular}

Fonte: Elaboração própria com base nas postagens da CGU.

"Transparência", tema mais abordado pela CGU, apresenta-se em 27,2\% das postagens (1.145). Essas publicações se dedicaram, em boa parte, a explicar como funciona a LAI, além de divulgar o Portal da Transparência do Governo Federal e de expor índices de transparência de estados e municípios.

Destaca-se que, quando são realizados os cruzamentos entre a variável "Tema da postagem" e as variáveis dummy, as postagens sobre transparência tendem a mencionar legislações específicas, a oferecer links para conteúdo externo e a não mencionar personalidades conhecidas do grande público. Mais exatamente, há 15,7 casos a mais do que o esperado de postagens classificadas nesse tema que mencionam normas legais (Tabela 3 do Documento Suplementar); há 2,4 casos a mais do que o esperado de postagens sobre transparência que apresentam links para conteúdo externo (Tabela 2 do 
Documento Suplementar); e há 7 casos a menos do que o esperado de postagens sobre transparência que mencionam personalidades ou autoridades (Tabela 4 do Documento Suplementar).

\#AcessoàInformação: Lembre-se! O serviço de solicitação de informações governamentais é gratuito. Apenas nas hipóteses de reprodução de documentos pelo órgão público consultado poderá ser cobrado exclusivamente o valor necessário ao ressarcimento do custo dos serviços e dos materiais utilizados. Conheça a \#LeideAcesso na íntegra e saiba todos os detalhes sobre 0 acesso às informações públicas: www.acessoainformacao.gov.br (Facebook - 20/6/2016) ${ }^{19}$.

822 municípios receberam nota zero no ranking de cumprimento da Lei de Acesso. Veja quais em http://ow.ly/USHy9 (Twitter - 20/11/2015) 20.

\#IndiretasCidadãs: É fundamental a participação dos cidadãos no controle do gasto público monitorando as ações governamentais e exigindo o uso adequado dos recursos públicos. Fique de olho! Acompanhe os recursos públicos federais transferidos para seu estado ou município e exija uma gestão proba dos governantes: www.portaldatransparencia.gov.br (Facebook $20 / 2 / 2015)^{21}$.

O segundo tema mais recorrente nas postagens é "Corrupção e demais irregularidades", predominante em 24,5\% do corpus (1032). Essas postagens abordam questões como tratados internacionais contra a corrupção, investigações das quais o ministério participa, listas de empresas impedidas de participar de processos licitatórios e englobam posts relacionados à campanha "pequenas corrupções do dia a dia", cujo objetivo é conscientizar os cidadãos a respeito de atitudes antiéticas (desde comprar produtos piratas até furar filas).

"Todo mundo faz" não é desculpa. \#DigaNão aos desvios de conduta e quebre a corrente! http://cgu.gov.br/diganao (Twitter - 19/10/2015)22.

\#DigaNão: Não é preciso ter superpoderes para combater o mal! Todos podemos mudar atitudes em nosso dia a dia contra os "pequenos" desvios de conduta. Afinal, os hábitos cotidianos de um povo podem refletir como são encarados os casos de corrupção com dinheiro público no país. As grandes

\footnotetext{
19 Ver em:

<https://www.facebook.com/cguonline/photos/a.379439358766803.92592.171477772896297/117888817 2155247/?type=3>. Acesso em: 7 set. 2020.

20 Ver em: <https://twitter.com/CGUonline/status/667692184347504640>. Acesso em: 7 set. 2020.

21 Ver em:

<https://www.facebook.com/cguonline/photos/a.379439358766803.92592.171477772896297/907946195

916114/?type $=3>$. Acesso em: 7 set. 2020.

22 Ver em: <https://twitter.com/CGUonline/status/656104112631762944>. Acesso em: 8 set. 2020.
} 
mudanças começam nos pequenos atos. \#FaçaSuaParte nesta luta por um país mais ético! cgu.gov.br/diganao (Facebook - 10/6/2015) ${ }^{23}$.

Em terceiro lugar, estão posts relacionados à "Participação". O assunto é predominante em $9,4 \%$ do corpus (396 publicações), e a maior parte dessas postagens trata de oportunidades de participação em conselhos municipais e de denúncias de cidadãos acerca de irregularidades no serviço público.

\#ControleSocial: Os conselhos foram criados para ajudar a prefeitura na tarefa de utilizar bem o dinheiro público. Os conselhos municipais são instâncias de exercício da \#cidadania que abrem espaço para a participação popular na gestão pública. Esses conselhos podem desempenhar, conforme o caso, funções de fiscalização, de mobilização, de deliberação ou de consultoria. Baixe agora mesmo a cartilha da CGU sobre \#controlesocial e aprenda mais sobre a atuação dos conselhos: http://goo.gl/zo64ha (Facebook - 17/8/2015) ${ }^{24}$.

As postagens classificadas na categoria "Agenda e atribuições da CGU" aparecem em quarto lugar, com 9\% das publicações (377) - e apenas quatro delas tratam da substituição da CGU pelo MTFC através da Medida Provisória 726/2016 (Brasil, 2016b). Em parte dessas publicações, a instituição se dedicou a explicar que, mesmo com as mudanças propostas via Medida Provisória, ela permaneceria com as mesmas funções. Os outros posts classificados na categoria tratam de eventos e entrevistas de integrantes da CGU, além de divulgar notas de esclarecimento e oportunidades de estágio no órgão.

\#MTFC: Ministério da Transparência, Fiscalização e Controle mantém funções da antiga CGU. A Controladoria-Geral da União (CGU) tornou-se oficialmente na última quinta-feira (12) o Ministério da Transparência, Fiscalização e Controle (MTFC), por meio da Medida Provisória 726, editada pelo Presidente da República em exercício, Michel Temer. A mudança de nomenclatura do órgão, no entanto, não altera as suas funções. O ministro da nova pasta, Fabiano Silveira, explica que a mudança no nome teve o intuito de dar ainda mais prestígio ao órgão (Facebook - 17/5/2016) ${ }^{25}$.

Já a categoria "Cursos e concursos" aparece em quinto lugar, com 7,5\% das postagens (315). Além de capacitações, são divulgados concursos de naturezas diversas, frequentemente voltados para crianças e adolescentes.

\footnotetext{
23 Ver em:

<https://www.facebook.com/cguonline/fotos/a.379439358766803.92592.171477772896297/9626424704 46486/?type=3>. Acesso em: 8 set. 2020.

24 Ver em:

<https://www.facebook.com/cguonline/photos/a.379439358766803.92592.171477772896297/995911167

119616/?type $=3>$. Acesso em: 7 set. 2020.

25 Ver em:

<https://www.facebook.com/cguonline/photos/a.379439358766803.92592.171477772896297/116079347

3964717/?type=3>. Acesso em: 7 set. 2020 .
} 
As postagens classificadas na categoria "Gestão pública" correspondem a 7,1\% do corpus (298 publicações). Essas publicações tratam de normas relativas à administração pública ou de fiscalizações de serviços públicos.

\#GestãoPública: É possível a assinatura de contratos guarda-chuva pela Administração Pública? Não. (...) A orientação dos órgãos de controle é no sentido de que a assinatura de contratos guarda-chuva não seja feita (...) (Facebook - 14/1/2015) ${ }^{26}$.

Os conteúdos classificados na categoria "Pensamentos", por sua vez, compreendem $5,5 \%$ do corpus ( 230 postagens). São textos que apenas divulgam frases relacionadas à ética e à civilidade, frequentemente citando seus autores.

\section{A informação é a moeda da democracia (Thomas Jefferson) (Twitter - $27 / 3 / 2015)^{27}$.}

A categoria "Feriados e datas comemorativas" se apresenta em 3,9\% das postagens (166). Essas publicações tratam do aniversário de capitais brasileiras, Dia da Mulher, Dia do Trabalhador, Dia da Consciência Negra e outras datas de relevância social.

Em seguida, a categoria "Outros" aparece com 3,2\% das postagens (136). Dois tipos de publicações se sobressaem nesse caso: respostas a usuários que não se enquadram em nenhuma das outras categorias e posts sobre o simulador de aposentadoria para servidores públicos.

Por fim, a categoria "Programas de civilidade e ética" aparece em último lugar, correspondendo a somente $2,8 \%$ do corpus (119 postagens). Os textos aqui classificados não se resumem a falar sobre ética (como ocorre na categoria pensamentos), mas propõem iniciativas e programas a exemplo do Portalzinho da CGU (<http://www.portalzinho.cgu.gov.br/>). O Instituto Maurício de Sousa também é mencionado em parte dessas publicações, já que mantém uma parceria com a CGU em relação ao programa "Um por todos e todos por um! Pela ética e cidadania", que disponibiliza materiais para serem trabalhados em escolas ${ }^{28}$.

Em síntese, as estatísticas descritivas demonstram que a maior parte dos posts da CGU utiliza os recursos "Presença de link" e "Apelo ao envolvimento do usuário". "Legislações específicas" são mencionadas em cerca de um quinto das postagens. Em relação aos links tornados disponíveis, a maior parte direciona os usuários ao site oficial da CGU, às redes sociais do órgão e ao Portal da Transparência. E, no que se refere ao conteúdo da postagem, a CGU mobiliza dois grandes tópicos em pouco mais da metade do corpus: "Transparência" e "Corrupção e demais irregularidades".

\footnotetext{
${ }^{26}$ Ver em:

<https://www.facebook.com/cguonline/photos/a.379439358766803.92592.171477772896297/859237267 453674/?type $=3>$. Acesso em: 7 set. 2020.

27 Ver em: <https://twitter.com/CGUonline/status/581426855170953216>. Acesso em: 07 set. 2020.

28 Ver em: <https://www.gov.br/cgu/pt-br/educacao-cidada/programas/upt>. Acesso em: 8 set. 2020.
} 
Esta subseção apresenta os testes de associação e os resíduos padronizados relativos às variáveis que constam no livro de códigos e às redes sociais Facebook e Twitter.

O Quadro 2 expõe, de forma decrescente, os valores do qui-quadrado e do $\mathrm{V}$ de Cramér a fim de verificar como as variáveis se comportam em cada rede social. Nota-se que a hipótese nula é rejeitada em todos os casos. Ou seja, há associação estatisticamente significativa entre as variáveis apresentadas. $\mathrm{E}$ quanto maior o valor do $\mathrm{V}$ de Cramér, maior é o grau de associação entre elas (Field, 2005). A maior associação ocorre entre "Rede social" e "Menção à personalidade ou autoridade" (29\%). Isso quer dizer que, em 29\% dos casos, a variação da "Menção à personalidade ou autoridade" é explicada pela rede social. No caso das variáveis "Apelo ao envolvimento dos usuários", "Tema da postagem", "Presença de link" e "Menção à legislação", as associações ocorrem em 27\%, 20\%, 10\% e 7\% dos casos, respectivamente:

\begin{tabular}{|c|c|c|}
\hline \multicolumn{3}{|c|}{$\begin{array}{c}\text { Quadro } 2 \\
\text { Postagens da CGU no Facebook e no Twitter } \\
\text { Valores de associação entre as variáveis }\end{array}$} \\
\hline & \multicolumn{2}{|c|}{ Rede social } \\
\hline & Qui-quadrado & V de Cramér \\
\hline Menção à personalidade ou autoridade & $356,038(0,000)$ & 0,291 \\
\hline Apelo ao envolvimento dos usuários & $326,396(0,000)$ & 0,278 \\
\hline Tema da postagem & $172,490(0,000)$ & 0,202 \\
\hline Presença de links & $43,872(0,000)$ & 0,102 \\
\hline Menção à legislação & $25,804(0,000)$ & 0,078 \\
\hline
\end{tabular}

Fonte: Elaboração própria com base nas postagens da CGU.

As Tabelas 3, 4, 5, 6 e 7 apresentam as porcentagens e os resíduos padronizados dos cruzamentos entre "Rede social" e as demais variáveis expostas no Quadro 2. Ressaltase que a ordem de apresentação das tabelas também segue os valores do qui-quadrado e do $\mathrm{V}$ de Cramér de forma decrescente. Isto é, os cruzamentos com maior grau de associação são apresentados primeiro. Todos os valores que estão acima de 1,96 ou abaixo de $-1,96$ indicam associações não aleatórias (ao se estabelecer um intervalo de confiança de $95 \%$ ) e, por isso, estão em destaque. 
Tabela 3

Cruzamento entre as variáveis "Rede social" e "Menção à personalidade ou autoridade"

\begin{tabular}{|l|l|c|c|}
\hline & & Facebook & Twitter \\
\hline \multirow{2}{*}{ Presença } & $\mathrm{N}(\%)$ & $234(19,8)$ & $83(2,7)$ \\
\cline { 2 - 4 } & $\mathrm{RP}$ & $\mathbf{1 5 , 4}$ & $\mathbf{- 9 , 6}$ \\
\hline \multirow{2}{*}{ Ausência } & $\mathrm{N}(\%)$ & $947(80,2)$ & $2.948(97,3)$ \\
\cline { 2 - 4 } & $\mathrm{RP}$ & $\mathbf{- 4 , 4}$ & $\mathbf{2 , 7}$ \\
\hline Total & $\mathrm{N}(\%)$ & $1.181(100)$ & $3.031(100)$ \\
\hline
\end{tabular}

Fonte: Elaboração própria com base nas postagens da CGU. Resíduos padronizados significativos em destaque.

Considerando-se a Tabela 3, nota-se que a "Menção à personalidade ou autoridade" ocorre com mais frequência no Facebook do que no Twitter (apenas 2,7\% dos tweets mencionam pessoas conhecidas do grande público). De acordo com os resíduos padronizados, há 15,4 casos a mais do que o esperado de postagens no Facebook com presença de "Menção à personalidade ou autoridade". Já no Twitter, há 9,6 casos a menos do que o esperado.

Os dados da Tabela 4, por sua vez, apontam que, no Facebook, há 9,4 casos a mais do que o esperado de postagens que convocam o usuário à participação; e 12,1 casos a menos do que o esperado de postagens que não o fazem. O Twitter está associado negativamente à presença de "Apelo ao envolvimento do usuário" ( $R P=-5,9)$ e positivamente $(\mathrm{RP}=7,5)$ à ausência desse recurso:

Tabela 4

Cruzamento entre as variáveis "Rede social" e "Apelo ao envolvimento dos usuários"

\begin{tabular}{|l|l|c|c|}
\hline & & Facebook & Twitter \\
\hline \multirow{3}{*}{ Presença } & N (\%) & $989(83,7)$ & $1.627(53,7)$ \\
\cline { 2 - 4 } & RP & $\mathbf{9 , 4}$ & $\mathbf{- 5 , 9}$ \\
\hline \multirow{3}{*}{ Ausência } & N (\%) & $192(16,3)$ & $1.404(46,3)$ \\
\cline { 2 - 4 } & RP & $\mathbf{- 1 2 , 1}$ & $\mathbf{7 , 5}$ \\
\hline Total & N (\%) & $1.181(100)$ & $3.031(100)$ \\
\hline
\end{tabular}

Fonte: Elaboração própria com base nas postagens da CGU.

Resíduos padronizados significativos em destaque.

A Tabela 5 evidencia os resíduos padronizados do cruzamento entre as variáveis "Rede social" e "Tema da postagem". Os maiores valores de resíduos padronizados estão na categoria "Feriados e datas comemorativas". No Facebook, há 10,3 casos a mais do que o esperado, e no Twitter, 6,4 casos a menos do que a expectativa: 
Tabela 5

Cruzamento entre as variáveis "Rede social" e "Tema da postagem"

\begin{tabular}{|c|c|c|c|}
\hline & & Facebook & Twitter \\
\hline \multirow{2}{*}{ Transparência } & $\mathrm{N}(\%)$ & $282(23,9)$ & $863(28,5)$ \\
\hline & $\mathrm{RP}$ & $-2,2$ & 1,4 \\
\hline \multirow{2}{*}{ Corrupção e demais irregularidades } & $\mathrm{N}(\%)$ & $263(22,3)$ & $769(25,4)$ \\
\hline & RP & $-1,5$ & 1,0 \\
\hline \multirow{2}{*}{ Participação } & $\mathrm{N}(\%)$ & $94(8)$ & $302(10)$ \\
\hline & RP & $-1,6$ & 1,0 \\
\hline \multirow{2}{*}{ Agenda e atribuições da CGU } & $\mathrm{N}(\%)$ & $92(7,8)$ & $283(9,3)$ \\
\hline & $\mathrm{RP}$ & $-1,3$ & 0,8 \\
\hline \multirow{2}{*}{ Cursos e concursos } & $\mathrm{N}(\%)$ & $99(8,4)$ & $216(7,1)$ \\
\hline & $\mathrm{RP}$ & 1,1 & $-0,7$ \\
\hline \multirow{2}{*}{ Gestão pública } & N (\%) & $102(8,6)$ & $196(6,5)$ \\
\hline & $\mathrm{RP}$ & 2,0 & $-1,3$ \\
\hline \multirow{2}{*}{ Pensamentos } & $\mathrm{N}(\%)$ & $65(5,5)$ & $165(5,4)$ \\
\hline & $\mathrm{RP}$ & 0,1 & 0 \\
\hline \multirow{2}{*}{ Feriados e datas comemorativas } & N (\%) & $117(9,9)$ & $49(1,6)$ \\
\hline & $\mathrm{RP}$ & 10,3 & $-6,4$ \\
\hline \multirow{2}{*}{ Outros } & $\mathrm{N}(\%)$ & $33(2,8)$ & $103(3,4)$ \\
\hline & $\mathrm{RP}$ & $-0,8$ & 0,5 \\
\hline \multirow{2}{*}{ Programas de civilidade e ética } & $\mathrm{N}(\%)$ & $34(2,8)$ & $85(2,8)$ \\
\hline & RP & 0,1 & $-0,1$ \\
\hline Total & $\mathrm{N}(\%)$ & $1.181(100)$ & $3.031(100)$ \\
\hline
\end{tabular}

Fonte: Elaboração própria com base nas postagens da CGU.

Resíduos padronizados significativos em destaque.

Destaca-se que a categoria "Transparência" está associada negativamente ao Facebook, uma vez que há 2,2 casos a menos do que o esperado de postagens abordando o tópico nessa rede social. Mesmo assim, a transparência é o assunto predominante das duas plataformas: $23,9 \%$ das publicações no Facebook e 28,5\% dos tweets foram classificados nessa categoria.

Em contrapartida ao que ocorre com as postagens sobre "Transparência", a categoria "Gestão pública" está associada positivamente ao Facebook, com 2,029 casos a mais do que o esperado em tal rede social. Muitas das postagens classificadas nessa categoria têm a intenção de divulgar normas relativas à administração pública e, por conta da não restrição de número de caracteres no Facebook, especula-se que se mostra mais conveniente abordá-la nessa rede social.

29 Ressalta-se que o resultado 2,0 está muito próximo de 1,96 (valor que limita as associações não aleatórias), indicando que, mesmo que a não aleatoriedade esteja presente na distribuição, ela ocorre em grau muito baixo. 
A Tabela 6 apresenta os resultados do cruzamento entre as variáveis "Rede social" e "Presença de link". Nota-se que, assim como ocorre com as variáveis "Menção à personalidade ou autoridade" e "Apelo ao envolvimento do usuário", a "Presença de link" está associada positivamente ao Facebook ( $R P=3,2)$. E há 4,6 casos a menos do que o esperado de postagens nessa rede social sem link algum. No caso do Twitter, há associação positiva com a ausência de link ( $R P=2,9$ ). Mesmo assim, trata-se de um recurso utilizado em mais da metade das postagens, nas duas redes sociais. Enquanto $75,9 \%$ dos posts no Facebook disponibilizam links para conteúdo externo, 65,3\% dos tweets o fazem.

Tabela 6

Cruzamento entre as variáveis "Rede social" e "Presença de link"

\begin{tabular}{|l|l|c|c|}
\hline & & Facebook & Twitter \\
\hline \multirow{2}{*}{ Presença } & $\mathrm{N}(\%)$ & $896(75,9)$ & $1.979(65,3)$ \\
\cline { 2 - 4 } & $\mathrm{RP}$ & $\mathbf{3 , 2}$ & $-1,9$ \\
\hline \multirow{2}{*}{ Ausência } & $\mathrm{N}(\%)$ & $285(24,1)$ & $1.052(34,7)$ \\
\cline { 2 - 4 } & $\mathrm{RP}$ & $\mathbf{- 4 , 6}$ & $\mathbf{2 , 9}$ \\
\hline Total & $\mathrm{N}(\%)$ & $1.181(100)$ & $3.031(100)$ \\
\hline
\end{tabular}

Fonte: Elaboração própria com base nas postagens da CGU. Resíduos padronizados significativos em destaque.

Por fim, a Tabela 7 apresenta as frequências e os resíduos padronizados do cruzamento entre as variáveis "Rede social" e "Menção à legislação". Novamente, a referida estratégia é mais utilizada no Facebook do que no Twitter. Os resíduos padronizados mostram associação positiva entre o Facebook e a presença de "Menção à legislação" (RP $=3,8)$ e associação negativa quando há ausência de "Menção à legislação" (RP = -2,0). No caso do Twitter, há 2,4 casos a menos do que o esperado de postagens mencionando dispositivos legais específicos.

Tabela 7

Cruzamento entre as variáveis "Rede social" e "Menção à legislação"

\begin{tabular}{|l|l|c|c|}
\hline & & Facebook & Twitter \\
\hline \multirow{3}{*}{ Presença } & $\mathrm{N}(\%)$ & $310(26,2)$ & $580(19,1)$ \\
\cline { 2 - 4 } & $\mathrm{RP}$ & $\mathbf{3 , 8}$ & $\mathbf{- 2 , 4}$ \\
\hline \multirow{2}{*}{ Ausência } & $\mathrm{N}(\%)$ & $871(73,8)$ & $2.451(80,9)$ \\
\cline { 2 - 4 } & $\mathrm{RP}$ & $\mathbf{- 2 , 0}$ & 1,2 \\
\hline \multirow{2}{*}{ Total } & $\mathrm{N}(\%)$ & $1.181(100)$ & $3.031(100)$ \\
\hline
\end{tabular}

Fonte: Elaboração própria com base nas postagens da CGU.

Resíduos padronizados significativos em destaque.

Em resumo, os resultados apresentados nesta seção confirmam que existem diferenças entre os padrões de postagem da CGU no Facebook e no Twitter. No que concerne às variáveis dummy ("Presença de link", "Apelo ao envolvimento dos usuários", 
"Menção à legislação" e "Menção à personalidade ou autoridade"), verifica-se que tais recursos são mais empregados no Facebook. Isso ocorre, provavelmente, porque, uma vez que não há restrição de caracteres na referida rede social, a CGU consegue, em uma só publicação, oferecer link para conteúdo externo, chamar o usuário à participação e, ainda, mencionar autoridades e legislações específicas. Em todo o corpus, 36 postagens utilizam esses quatro recursos simultaneamente - e todas elas estão no Facebook. Isso implica que a configuração de cada rede social gera um impacto determinante sobre os meios e modos como a comunicação digital é organizada. A publicação abaixo ilustra o argumento:

\#AoVivo: Acompanhe a transmissão da conferência sobre aspectos da Lei Anticorrupção. Hoje, das $9 \mathrm{~h}$ às $18 \mathrm{~h}$, será transmitida ao vivo a $2^{\mathrm{a}}$ Conferência Lei \#EmpresaLimpa, que acontece no Rio de Janeiro. O evento debaterá temas relacionados à Lei Anticorrupção (Lei 12.846/2013) e à integridade no setor privado, bem como premiará as empresas aprovadas no Pró-Ética 2015. Após a abertura do evento, o ministro da CGU, Valdir Simão, entregará o prêmio às empresas Pró-Ética 2015, iniciativa que reconhece empresas comprometidas com a integridade, a transparência, a prevenção e o combate à corrupção no ambiente corporativo. Em seguida, a partir das $11 \mathrm{~h} 30$, serão realizadas palestras sobre licitações e exportações, compliance no mercado brasileiro e passo a passo sobre programa de integridade. Confira a programação do evento em http://ow.ly/UkWwt Acompanhe a transmissão da conferência pelo link http://liveevents.com.br/leiempresalimpa/ (Facebook $9 / 11 / 2015)^{30}$.

No caso da variável "Tema da postagem", conforme exposto na Tabela 5, apenas três categorias apresentam distribuições não aleatórias: "Transparência", "Gestão pública" e "Feriados e datas comemorativas". No caso de "Transparência", há um menor número de postagens no Facebook do que o esperado. E as categorias "Gestão pública" e "Feriados e datas comemorativas" tendem a aparecer mais nessa rede social.

Ocorre que, no Twitter, algumas postagens sobre "Transparência" com o mesmo conteúdo se repetem de forma recorrente, enquanto, no Facebook, a CGU tem espaço para divulgar assuntos concernentes à administração pública de forma mais detalhada. No que se refere à categoria "Feriados e datas comemorativas", os valores dos resíduos padronizados chamam atenção porque essas postagens são significativamente mais frequentes no Facebook (Tabela 5), o que sugere uma estratégia de comunicação diferenciada adotada pelo órgão, devido às diferenças entre os usuários das duas redes sociais.

\footnotetext{
30 Ver em:

<https://www.facebook.com/cguonline/photos/a.379439358766803.92592.171477772896297/104424017 2286715/?type=3>. Acesso em: 7 set. 2020 .
} 
Diferenças nos padrões de postagem da CGU durante os governos de Dilma Rousseff e Michel Temer

A partir de agora, o artigo se debruça sobre as associações entre as variáveis indicadas anteriormente e os governos Dilma Rousseff e Michel Temer. O Quadro 3 mostra que a única variável que não está associada aos governos é a "Presença de link", uma vez que o nível de significância do teste de qui-quadrado está acima do limite crítico. Isso quer dizer que tal recurso não variou conforme a mudança de chefe do Poder Executivo Federal (por isso, não haveria sentido em detalhar essa variável separadamente). Nos outros casos, há associação significativa, ainda que em níveis baixos:

\section{Quadro 3}

Postagens da CGU nos governos de Dilma Rousseff e Michel Temer Valores de associação entre as variáveis

\begin{tabular}{|l|c|c|}
\hline \multirow{2}{*}{} & \multicolumn{2}{|c|}{ Governo } \\
\cline { 2 - 3 } & Qui-quadrado & V de Cramér \\
\hline Tema da postagem & $37,371(0,000)$ & 0,094 \\
\hline Apelo ao envolvimento dos usuários & $23,332(0,000)$ & 0,074 \\
\hline Menção à legislação & $16,320(0,000)$ & 0,062 \\
\hline Menção à personalidade ou autoridade & $5,751(0,000)$ & 0,037 \\
\hline Presença de link & $0,663(0,416)$ & - \\
\hline
\end{tabular}

Fonte: Elaboração própria com base nas postagens da CGU.

Destaca-se, primeiramente, que há uma diferença substancial no número de postagens da CGU durante os governos de Rousseff e Temer. Durante o mandato da expresidente eleita pelo Partido dos Trabalhadores, a CGU publicou 3.221 vezes (somandose os posts das duas redes sociais estudadas). Já durante os meses relativos ao governo Temer, foram 991 posts. Ao longo do ano de 2015, a média de postagens por mês da CGU, no Facebook e no Twitter, foi de 231 publicações. A partir de janeiro de 2016 (portanto, ainda antes de Michel Temer assumir a presidência), a CGU diminuiu a frequência de postagens, e a média para o ano de 2016 ficou em 119. Essa redução pode ter ocorrido devido à rotatividade de ministros no intervalo aqui considerado. Quatro nomes ocuparam a direção do órgão no período: Carlos Higino substituiu Valdir Simão em 21 de dezembro de 2015, mas permaneceu no cargo apenas até fevereiro do ano seguinte. Luiz Navarro assumiu em seguida e comandou a instituição até 12 de maio de 2016. Quando Michel Temer assumiu a presidência interinamente, logo designou Fabiano Silveira para ser o ministro da nova pasta. Este foi afastado do cargo ainda em 31 de maio, sendo, então, substituído por Torquato Jardim ${ }^{31}$.

A Tabela 8 apresenta os resíduos padronizados e as frequências do cruzamento entre as variáveis "Governo" e "Tema da postagem". As distribuições não são aleatórias

31 Ver em: <https://www.gov.br/cgu/pt-br/composicao/ministro>. Acesso em: 2 nov. 2019. 
no caso de três categorias: "Transparência", "Corrupção e demais irregularidades" e "Pensamentos".

Tabela 8 Cruzamento entre as variáveis "Governo" e "Tema da postagem"

\begin{tabular}{|c|c|c|c|}
\hline & & Rousseff & Temer \\
\hline \multirow{2}{*}{ Transparência } & N (\%) & $918(28,5)$ & $227(22,9)$ \\
\hline & $\mathrm{RP}$ & 1,4 & $-2,6$ \\
\hline \multirow[t]{2}{*}{ Corrupção e demais irregularidades } & $\mathrm{N}(\%)$ & $743(23,1)$ & $289(29,2)$ \\
\hline & $\mathrm{RP}$ & $-1,6$ & 3,0 \\
\hline \multirow{2}{*}{ Participação } & N (\%) & $311(9,7)$ & $85(8,6)$ \\
\hline & $\mathrm{RP}$ & 0,5 & $-0,8$ \\
\hline \multirow{2}{*}{ Agenda e atribuições da CGU } & N (\%) & $296(9,2)$ & $79(8)$ \\
\hline & $\mathrm{RP}$ & 0,5 & $-1,0$ \\
\hline \multirow{2}{*}{ Cursos e concursos } & $N(\%)$ & $252(7,8)$ & $63(6,4)$ \\
\hline & $\mathrm{RP}$ & 0,7 & $-1,3$ \\
\hline \multirow{2}{*}{ Gestão pública } & N (\%) & $222(6,9)$ & $76(7,7)$ \\
\hline & $\mathrm{RP}$ & $-0,4$ & 0,7 \\
\hline \multirow{2}{*}{ Pensamentos } & N (\%) & $158(4,9)$ & $72(7,3)$ \\
\hline & $\mathrm{RP}$ & $-1,3$ & 2,4 \\
\hline \multirow{2}{*}{ Feriados e datas comemorativas } & $\mathrm{N}(\%)$ & $119(3,7)$ & $47(4,7)$ \\
\hline & $\mathrm{RP}$ & $-0,7$ & 1,3 \\
\hline \multirow{2}{*}{ Outros } & $\mathrm{N}(\%)$ & $104(3,2)$ & $32(3,2)$ \\
\hline & $\mathrm{RP}$ & 0 & 0 \\
\hline \multirow{2}{*}{ Programas de civilidade e ética } & $N(\%)$ & $98(3)$ & $21(2)$ \\
\hline & $\mathrm{RP}$ & 0,7 & $-1,3$ \\
\hline Total & N (\%) & $3.221(100)$ & $991(100)$ \\
\hline
\end{tabular}

Fonte: Elaboração própria com base nas postagens da CGU.

Resíduos padronizados significativos em destaque.

Verifica-se que, enquanto as postagens sobre "Transparência" estão associadas negativamente ao governo Temer, publicações que enfatizam "Corrupção e demais irregularidades" se encontram associadas positivamente a tal governo. Isso quer dizer que, após o afastamento de Dilma Rousseff, a CGU passou a publicar menos sobre "Transparência" e mais sobre "Corrupção" - ainda que esses dois assuntos permaneçam sendo os mais recorrentemente tratados pela CGU durante as duas gestões. A categoria "Pensamentos", por sua vez, está associada positivamente ao governo Temer: há 2,4 casos a mais dessas postagens do que o esperado.

Quanto às variáveis dummy, nota-se, com base na Tabela 9, que a presença da variável "Apelo ao envolvimento do usuário" está associada positivamente ao governo Temer $(R P=2,6)$, enquanto a ausência desse recurso está associada negativamente a 
esse governo ( $R P=-3,3$ ). Isso significa que, mesmo que a CGU, durante os dois governos estudados, tenha encorajado os usuários à participação em mais da metade de suas postagens, essa estratégia foi mais utilizada na gestão de Temer.

\section{Tabela 9}

Cruzamento entre as variáveis "Governo" e

"Apelo ao envolvimento dos usuários"

\begin{tabular}{|l|l|c|c|}
\hline \multirow{2}{*}{ Presença } & & Rousseff & Temer \\
& $\mathrm{N}(\%)$ & $1.936(60,1)$ & $680(68,6)$ \\
\cline { 2 - 4 } & $\mathrm{RP}$ & 1,4 & $\mathbf{2 , 6}$ \\
\hline \multirow{2}{*}{ Ausência } & $\mathrm{N}(\%)$ & $1.285(39,9)$ & $311(31,4)$ \\
\cline { 2 - 4 } & $\mathrm{RP}$ & 1,8 & $\mathbf{- 3 , 3}$ \\
\hline Total & $\mathrm{N}(\%)$ & $3.221(100)$ & $991(100)$ \\
\hline
\end{tabular}

Fonte: Elaboração própria com base nas postagens da CGU.

Resíduos padronizados significativos em destaque.

Já a Tabela 10 apresenta o cruzamento entre as variáveis "Governo" e "Menção à legislação". O resíduo padronizado mostra distribuição não aleatória apenas entre o governo Temer e a referida variável $(R P=-3,1)$. Em outras palavras, durante a administração Temer, houve uma tendência de que as postagens da CGU não mencionassem legislações específicas.

Tabela 10

Cruzamento entre as variáveis "Governo" e "Menção à legislação"

\begin{tabular}{|l|l|l|c|c|}
\hline \multirow{2}{*}{ Presença } & & Rousseff & Temer \\
\cline { 2 - 5 } & & N (\%) & $726(22,5)$ & $164(16,5)$ \\
\hline \multirow{2}{*}{ Ausência } & RP & 1,7 & $\mathbf{- 3 , 1}$ \\
\cline { 2 - 5 } & & N (\%) & $2.495(77,5)$ & $827(83,5)$ \\
\hline Total & RP & $-0,9$ & 1,6 \\
\hline
\end{tabular}

Fonte: Elaboração própria com base nas postagens da CGU.

Resíduos padronizados significativos em destaque.

Por fim, a Tabela 11 expõe a existência de uma associação positiva entre o governo Temer e a presença de "Menção à personalidade ou autoridade" ( $R P=2,0)^{32}$. De qualquer forma, ao longo das duas gestões, as frequências comprovam que a CGU pouco se remeteu a autoridades ou pessoas conhecidas do grande público.

\footnotetext{
32 Novamente, o valor do resíduo padronizado fica em apenas 2,0, indicando associação não aleatória, mas em grau muito baixo.
} 
Tabela 11

Cruzamento entre as variáveis "Governo" e "Menção à personalidade ou autoridade"

\begin{tabular}{|l|l|c|c|}
\hline \multirow{2}{*}{ Presença } & & Rousseff & Temer \\
& N (\%) & $225(7)$ & $92(9,3)$ \\
\cline { 2 - 4 } & RP & $-1,1$ & $\mathbf{2 , 0}$ \\
\hline \multirow{2}{*}{ Ausência } & $\mathrm{N}(\%)$ & $2.996(93)$ & $899(90,7)$ \\
\cline { 2 - 4 } & RP & 0,3 & $-0,6$ \\
\hline Total & $\mathrm{N}(\%)$ & $3.221(100)$ & $991(100)$ \\
\hline
\end{tabular}

Fonte: Elaboração própria com base nas postagens da CGU. Resíduos padronizados significativos em destaque.

Em resumo, os resultados apresentados demonstram que, durante o governo de Michel Temer, a CGU publicou menos sobre "Transparência" e mais sobre "Corrupção" e "Pensamentos". Além disso, a gestão que assumiu após o impeachment de Dilma Rousseff investiu mais em "Apelo ao envolvimento do usuário" e "Menção à personalidade ou autoridade", enquanto desprivilegiou "Menção à legislação".

A seção a seguir retoma as três questões norteadoras da pesquisa e discute os resultados a partir da literatura pertinente.

\section{Discussão dos resultados e conclusões}

A primeira questão de pesquisa proposta pelo artigo se referiu à frequência do tema da transparência pública e à forma como ele é mobilizado pela Controladoria-Geral da União em seus perfis no Facebook e no Twitter. Os resultados apontam que, nas duas plataformas estudadas, a CGU prioriza dois temas: transparência e corrupção. Além disso, em mais da metade dos posts, a instituição encoraja os cidadãos a se engajarem em atividades de participação política. Quando trata do tema da transparência pública, os dados resultantes demonstram que a instituição em tela tende a oferecer links para conteúdo externo e a mencionar legislações específicas (ver Tabelas 2 e 3 do Documento Suplementar). Uma vez que o dispositivo legal mais divulgado pela CGU foi a Lei de Acesso à Informação e que a maior parte dos links disponibilizados levava os usuários ao site oficial do órgão e ao Portal da Transparência, conclui-se que a referida instituição tem empregado suas redes sociais a fim de instruir os cidadãos a respeito desse tema, cumprindo com o propósito de tornar as informações públicas mais compreensíveis (Porumbescu, 2017; Secom, 2014), além de investir no engajamento dos cidadãos em atividades políticas - em consonância com experiências anteriores já identificadas pela literatura (Bertot, Jaeger e Grimes, 2010; Graham, 2014).

Contudo, é importante fazer duas ressalvas a esta altura. Em primeiro lugar, a transparência acessível nem sempre equivale à transparência acessada (Schudson, 2020). Isto é, mesmo que as redes sociais digitais possam facilitar a comunicação entre 
governantes e governados, as instituições públicas não são necessariamente capazes de atingir a todos os cidadãos - e, mesmo que conseguissem, há cidadãos que permaneceriam desinteressados em consumir o conteúdo tornado disponível. No caso dos 3.031 tweets aqui analisados ${ }^{33}$, por exemplo, a média de curtidas, respostas e retweets às postagens classificadas na categoria "Pensamentos" chega a ser mais do que o dobro da média de engajamento encontrada nas postagens sobre "Transparência" (ver Tabela 6 do Documento Suplementar). Em outras palavras, este artigo, ainda que se debruce sobre o que a CGU trata em seus perfis de redes sociais digitais, aponta caminhos para que a entidade mapeie de forma mais eficaz o comportamento do público que a segue em redes sociais - o que permite otimizar e tornar mais eficazes as políticas de elaboração e compartilhamento de conteúdo.

Em segundo lugar, é preciso ressaltar que a transparência não é neutra - o que significa que ela pode sofrer instrumentalização política (Wood e Aronczyk, 2020). No caso da CGU, contudo, os resultados apontam que a promoção de imagem de agentes públicos não é algo recorrente (somente $7,5 \%$ das postagens mencionam personalidades ou autoridades) - o que contraria as preocupações levantadas por Dror (1999) e Urbinati (2013).

De qualquer modo, a contribuição de Graber (2003) é pertinente para compreender modos alternativos de instrumentalização da comunicação pública - que nem sempre ficam evidentes apenas pelo estudo do conteúdo veiculado. A autora afirma que instituições públicas, naturalmente, evitam mentir em sua comunicação oficial, preferindo enfatizar "desirable news or slighting undesirable matters are acceptable practices. Good news is shouted, and bad news is whispered" (p. 229). Foi o que ocorreu no caso da MP 726/2016. Uma vez que as transformações na estrutura e nas atribuições do órgão foram criticadas por especialistas e servidores da instituição, apenas quatro postagens durante todo o período estudado mencionaram o referido dispositivo. Ou seja, a CGU evitou comentar o assunto nas redes sociais na tentativa de preservar sua imagem. Em consonância com tal argumento, um dos entrevistados por Sodré (2014) afirmou, pouco tempo antes, que "o que for dito nas redes reflete o posicionamento da Controladoria-Geral da União. A imagem da instituição é colocada à prova a cada resposta dada ou post publicado" (p. 149).

A segunda questão de pesquisa sob escrutínio partiu da premissa de que Facebook e Twitter dispõem de estruturas e configurações distintas, assim como contingentes de usuários nem sempre coincidentes. Diante disso, quais estratégias de comunicação a CGU privilegia nas duas redes sociais? Os resultados demonstram que, de fato, esse órgão adota abordagens singulares em cada plataforma, uma vez que os resultados de todas as variáveis analisadas estão associados significativamente a cada rede social em questão. Todos os recursos indicados pelas variáveis dummy ("Presença de link"; "Apelo ao envolvimento do usuário"; "Menção à legislação"; e "Menção à personalidade ou autoridade") são proporcionalmente mais utilizados no Facebook do que no Twitter. No que

33 Só foram coletadas curtidas, respostas e compartilhamentos referentes às postagens do Twitter. 
concerne ao tema, três categorias apresentaram distribuições não aleatórias, conforme os resíduos padronizados: "Transparência" (associada negativamente ao Facebook), "Gestão pública" e "Feriados e datas comemorativas" (as duas últimas categorias estão associadas positivamente ao Facebook).

A utilização dos recursos indicados pelas variáveis dummy ocorre de maneira mais frequente no Facebook, provavelmente por conta da não restrição quanto ao número de caracteres. Em uma mesma postagem, a CGU consegue oferecer links, convocar os usuários à participação, mencionar leis específicas e autoridades ou personalidades. No Twitter, não há como isso ocorrer em uma única publicação - sobretudo pelo fato de que, no período considerado neste artigo, cada tweet poderia ter no máximo 140 caracteres. Portanto, as diferentes funcionalidades, configurações e estruturas das redes sociais digitais interferem no processo comunicativo, corroborando o que foi apontado por investigações anteriores (Bossetta, 2018; Luna-Reyes, 2017; Marques, 2016b; Davis, 2015).

Ademais, no caso dos temas das postagens, a variação entre "Transparência", "Corrupção e demais irregularidades" e "Feriados e datas comemorativas" também pode decorrer da diferença quanto à base de usuários de cada plataforma. Ao aplicar entrevistas semiestruturadas a um assessor de imprensa e a um analista de comunicação da CGU, Sodré (2014) 34 demonstra que tais profissionais reconhecem que a atuação do órgão difere nas duas redes, uma vez que os seguidores não possuem os mesmos perfis educacionais. Um dos entrevistados destaca, inclusive, que os usuários do Twitter possuem um perfil mais técnico quando comparado ao dos usuários do Facebook. Essas diferenças colaboram para explicar por que a CGU trata com mais frequência de temas mais próximos do cotidiano dos cidadãos (como corrupção e feriados) nessa última rede social.

A terceira e última questão de pesquisa visava investigar se, e em que medida, as rotinas de comunicação da CGU em redes sociais foram transformadas a partir da transição entre os governos de Dilma Rousseff e Michel Temer. A análise empírica aponta, de fato, para a existência de alterações na política de comunicação do órgão, ainda que não sejam radicais. Isso porque, mesmo que a transição governamental tenha ocasionado modificações no teor das postagens da CGU, as associações entre as variáveis se mostraram relativamente baixas.

De acordo com os resíduos padronizados, as publicações da Controladoria-Geral da União estudadas neste artigo e que foram publicadas durante o governo de Michel Temer tendem a tratar menos do tema "Transparência" e mais de "Corrupção e demais irregularidades" e "Pensamentos". Além disso, a mudança governamental também aumenta a presença de "Apelo ao envolvimento do usuário" e de "Menção à personalidade ou autoridade". Em contrapartida, a variável "Menção à legislação" está associada

\footnotetext{
34 Uma vez que o quadro de funcionários responsáveis pelas redes sociais da CGU não sofreu grandes mudanças entre 2012 e 2017 (informação obtida através da Lei de Acesso à Informação) e que as entrevistas realizadas por Sodré (2014) são bastante completas e detalhadas, optou-se pela não aplicação de novos questionários.
} 
negativamente à administração que assumiu o Poder Executivo após o impeachment de Rousseff.

O crescimento no número de postagens sobre corrupção durante o período da gestão de Michel Temer pode indicar uma tentativa da CGU de - por mais complexo que possa parecer - afastar a imagem do então presidente das denúncias de corrupção que recaíram sobre os governos petistas. Em outras palavras, não obstante Michel Temer ter sido acusado de corrupção, lavagem de dinheiro e obstrução de justiça enquanto ainda exercia o cargo de presidente da República ${ }^{35}$, a CGU pode ter tentado contemplar a agenda anticorrupção em suas postagens - ainda que tal observação seja feita no plano especulativo.

Ademais, a ampliação na frequência de postagens classificadas na categoria "Pensamentos" durante a gestão do MDB sugere uma estratégia de comunicação que privilegia temas que recebem maior interação dos usuários - afinal, publicações de tal natureza apresentam a maior média de engajamento no Twitter quando comparadas a posts sobre outros temas (ver Tabela 6 do Documento Suplementar). Ressalte-se, todavia, que essa maior projeção ocorreu em detrimento das postagens sobre transparência sendo que estas, sim, podem orientar com maior eficácia os cidadãos a respeito do controle social sobre a coisa pública.

Visto que a equipe responsável pelas redes sociais da CGU se manteve praticamente a mesma entre 2012 e 2017 (isto é, não houve mudanças significativas no quadro de profissionais que atuam na gestão das redes sociais do órgão ao longo do período estudado por este artigo $)^{36}$, é possível que os padrões distintos de uso das redes sociais digitais tenham sido ocasionados não apenas pela transição presidencial, mas também devido à alternância de ministros. Afinal, mesmo que a equipe de servidores efetivos seja mantida, as diretrizes do novo gestor podem impulsionar ênfases distintas na produção de conteúdo, modificando-se o modo pelo qual as entidades se apresentam publicamente.

Antes de encerrar este artigo, é importante apontar uma limitação pertinente. Conforme se pôde constatar, a análise de conteúdo ora empregada não considerou fotos e vídeos que, eventualmente, podem acompanhar as publicações de órgãos públicos em redes sociais digitais. Essa decisão se deveu à dimensão do corpus e à impossibilidade de avaliar imagens e vídeos com a mesma categorização utilizada para textos.

Já em relação à agenda para pesquisas futuras, sugere-se a possibilidade de expandir a investigação a instituições públicas que não se refiram ao Poder Executivo Federal. Tribunais de Contas, por exemplo, também realizam atividades de controle, ainda que tenham atuação marcadamente distinta da CGU do ponto de vista institucional. Ademais, novos trabalhos podem se dedicar a compreender de que forma os cidadãos consomem os conteúdos publicados por instituições do Estado e do governo por meio de

35 Ver em: <https://veja.abril.com.br/politica/durante-presidencia-temer-foi-denunciado-tres-vezes-pelapgr/>. Acesso em: 9 set. 2020.

36 Ver Figura 1 do Documento Suplementar. 
redes sociais digitais. Se, do ponto de vista prático, este artigo constatou que a CGU prioriza o tema da transparência e convoca os cidadãos à participação, em que medida os usuários se sentem compelidos a fiscalizar e investir no controle social da coisa pública?

\section{Referências bibliográficas}

AL-AUfI, A. S., et al. "Citizens' perceptions of government's participatory use of social media". Transforming Government: People, Process and Policy, vol. 11, n² 2, p. 174-194, 2017.

ALMADA, M. P. "Avaliação da e-transparência em portais de governos nacionais: uma comparação entre Brasil, Estados Unidos e Reino Unido". Tese de Doutorado em Comunicação e Cultura Contemporâneas. Faculdade de Comunicação, Universidade Federal da Bahia, Salvador, 2016.

AMORIM, P. K. "Democracia e internet: a transparência de gestão nos portais eletrônicos das capitais brasileiras". Tese de Doutorado em Comunicação e Cultura Contemporâneas. Faculdade de Comunicação, Universidade Federal da Bahia, Salvador, 2012.

ANANNY, M.; CRAWFORD, K. "Seeing without knowing: limitations of the transparency ideal and its application to algorithmic accountability". New Media \& Society, vol. 20, n 3, p. 973-989, 2018.

ANGELI, A. E. "Accountability e internet em uma perspectiva comparada: a atuação digital das Controladorias Públicas na América Latina". Dissertação de Mestrado em Ciência Política, Setor de Ciências Humanas, Letras e Artes, Universidade Federal do Paraná, Curitiba, 2017.

AngéLICO, F. Transparência, accountability e tecnologia. In: MendonçA, R. F.; PereirA, M. A.; FILGUeIRAS, F. (eds.). Democracia digital: publicidade, instituições e confronto político. Belo Horizonte: Editora UFMG, p. 113-130, 2016.

BARDIN, L. Análise de conteúdo. Lisboa: Edições 70, 1977.

BAUHR, M.; GRIMES, M. "Indignation or resignation: the implications of transparency for societal accountability". Governance: An International Journal of Policy, Administration, and Institutions, vol. 27, n०2, p. 291-320, 2014.

Bentham, J. "Da publicidade". Revista Brasileira de Ciência Política, vol. 6, p. 277-294, 2011.

BeRTOt, C.; JAEger, P. T.; GRIMES, J. M. "Using ICTs to create a culture of transparency: egovernment and social media as openness and anti-corruption tools for societies". Government Information Quarterly, n²7, p. 264-271, 2010.

BERTOT, C.; JAEGER, P. T.; GRIMES, J. M. "Promoting transparency and accountability through ICTs, social media, and collaborative e-government". Transforming Government: People, Process and Policy, vol. 6, n० 1, p. 78-91, 2012.

BODEI, R. "From secrecy to transparency: reason of state and democracy". Philosophy \& Social Criticism, vol. 37, n 8, p. 889-898, 2011.

Bonsón, E., et al. "Local e-government 2.0: social media and corporate transparency in municipalities". Government Information Quarterly, vol. 29, p. 123-132, 2012.

BossetTA, M. "The digital architectures of social media: comparing political campaigning on Facebook, Twitter, Instagram, and Snapchat in the 2016 U.S. election". Journalism \& Mass Communication Quarterly, 2018. 
BRAGA, S. S. "Podem as novas tecnologias de informação e comunicação auxiliar na consolidação das democracias? Um estudo sobre a informatização dos órgãos legislativos na América do Sul". Opinião Pública, vol. 13, n 1, p. 1-50, 2007.

BRASIL. Medida Provisória n 726, de 12 maio 2016. Altera e revoga dispositivos da Lei no 10.683, de 28 de maio de 2003, que dispõe sobre a organização da Presidência da República e dos Ministérios. Diário Oficial da União, Brasília, DF, maio 2016a.

Lei $n^{\circ} 13.341$, de 29 de setembro de 2016. Altera as Leis $n^{\circ} 10.683$, de 28 de maio de 2003, que dispõe sobre a organização da Presidência da República e dos Ministérios, e 11.890, de 24 de dezembro de 2008, e revoga a Medida Provisória no 717, de 16 de março de 2016. Diário Oficial da União, Brasília, DF, set. 2016b.

. Lei n 13.844, de 18 de junho de 2019. Estabelece a organização básica dos órgãos da Presidência da República e dos Ministérios. Diário Oficial da União, Brasília, DF, jun. 2019.

Cucciniello, M.; Porumbescu, G.; GrimmelikHuijsen, S. "25 years of transparency research: evidence and future directions". Public Administration Review, vol. 77, p. 32-44, 2016.

DAVIS, J. L. Social media. In: MAZzolenI, G. (ed.). The international encyclopedia of political communication. Hoboken: Wiley Blackwell, 2015.

DePaula, N.; Dincelli, E. "Information strategies and affective reactions: how citizens interact with government social media content". First Monday, vol. 23, n 4, 2018.

DROR, Y. Transparency and openness of quality. In: KELLY, M. (ed.). Openness and transparency in governance: challenges and opportunities. Maastricht: NISPAcee, p. 62-71, 1999.

ELLISON, N. B.; BOYD, D. Sociality through social network sites. In: DUTTON, W. H. (ed.). The Oxford handbook of internet studies. Oxford: University Press, p. 151-172, 2013.

ERNST, N., et al. "Extreme parties and populism: an analysis of Facebook and Twitter across six countries". Information, Communication \& Society, vol. 20, n 9, p. 1.347-1.364, 2017.

ETZioni, A. The limits of transparency. In: AlloA, E.; THOMÃ, D. (eds.). Transparency, society and subjectivity. Cham: Palgrave Macmillan, p. 179-201, 2018.

. "Transparency is overrated" (online). The Atlantic, 2014. Disponível em:

<http://www.theatlantic.com/politics/archive/2014/01/transparency-is-overrated/282990/>. Acesso em: 24 nov. 2019.

FERRACIOLI, P., HeRMAN, F. "Habilitando o cidadão para a transparência. Análise de portais estaduais do Executivo e Legislativo". Agenda Política, vol. 7, no 1, p. 217-238, 2019.

FIELD, A. Discovering statistics with SPSS, 3a ed. London: Sage, 2005.

FilgueIRAS, F. "Além da transparência: accountability e política da publicidade". Lua Nova: Revista de Cultura e Política, n 84, p. 65-94, 2011.

FUnG, A. "Infotopia: unleashing the democratic power of transparency". Politics \& Society, vol. 41, $n^{\circ} 2$, p. 183-212, 2013.

Gomes, W.; AMORIM, P. K. D. F.; ALmADA, M. P. "Novos desafios para a ideia de transparência pública". E-Compós, vol. 21, n² 2, 2018.

Graber, D. The power of communication. Washington: CQ Press, 2003.

Graham, M. W. "Government communication in the digital age: social media's effect on local government public relations". Public Relations Inquiry, vol. 3, n 3, p. 361-376, 2014. 
Grimmelikhuijsen, S.; Porumbescu, G.; Hong, B. "The effect of transparency on trust in government: a cross-national comparative experiment". Public Administration Review, vol. 73, n 4, p. 575-586, 2013.

GUILLAMÓN, M. D., et al. "Factors influencing social media use in local governments: the case of Italy and Spain". Government Information Quarterly, vol. 33, no 3, 2016.

GunAWONG, P. "Open government and social media: a focus on transparency social". Social Science Computer Review, p. 1-12, 2014.

Hansen, K. H.; FlyVerbom, M. "The politics of transparency and the calibration of knowledge in the digital age". Organization, vol. 22, n 6, p. 872-889, 2015.

HeALD, D. Varieties of transparency. In: HoOd, C.; HeALD, D. (eds.). Transparency: the key to better governance. New York: Oxford University Press, p. 25-43, 2006.

Hoch, P. A.; Rigui, L. M.; SilvA, R. L. "Desafios à concretização da transparência ativa na internet, à luz da Lei de Acesso à Informação pública: análise dos portais dos Tribunais Regionais Federais". Revista Direitos Emergentes na Sociedade Global, vol. 1, n 2, 2012.

Hood, C. Transparency in historical perspective. In: HOOD, C.; HEALD, D. (eds.). Transparency: the key to better governance. New York: Oxford University Press, p. 3-24, 2006.

KANT, I. A paz perpétua. Covilhã: LusoSofiapress, 2008.

KIM, S. K.; PARK, M. J.; RHO, J. J. "Effect of the government's use of social media on the reliability of the government: focus on Twitter". Public Management Review, vol. 17, n 3, p. 328-355, 2015.

KRIPPEndorfF, K. Content analysis: an introduction to its methodology. London: Sage, 2004.

LOURENÇO, R. "An analysis of open government portals: a perspective of transparency for accountability". Government Information Quarterly, vol. 32, n 3, p. 323-332, 2015.

LUNA-REYES, L. F. "Opportunities and challenges for digital governance in a world of digital participation". Information Polity, vol. 22, p. 197-205, 2017.

MARgetts, H. "The internet and transparency". The Political Quarterly, vol. 82, n 4, p. 518-521, 2011.

MARques, F. P. J. Internet e transparência política. In: MendonçA, R. F.; Pereira, M. A.; Filgueiras, F. (orgs.). Democracia digital: publicidade, instituições e confronto político. Belo Horizonte: Editora UFMG, p. 55-78, 2016a.

. Ciberpolítica: conceitos e experiências. Salvador, Editora da UFBA, 2016b.

MARQUeS, F. P. J., et al. "What do state institutions say? Twitter as a public communication tool during the impeachment of Dilma Rousseff". Brazilian Political Science Review, vol. 13, n 3, p. 132, 2019.

MeRGEL, I. "A framework for interpreting social media interactions in the public sector". Government Information Quarterly, 2013.

Miola, E.; MARQUES, F. P. J. "Comunicação pública do Ministério da Saúde no Facebook: uma análise das campanhas contra o Aedes aegypti no 'verão do Zika'". Revista Eletrônica de Comunicação, Informação e Inovação em Saúde, vol. 14, n 1, 2020.

MoORE, S. "Towards a sociology of institutional transparency: openness, deception and the problem of public trust". Sociology, vol. 52, n², p. 416-430, 2018. 
Neuendorf, K. A.; Kumar, A. Content analysis. In: Mazzoleni, G. (ed.). The international encyclopedia of political communication. Hoboken, New Jersey: Wiley Blackwell, 2015.

Picazo-Vela, S.; Gutiérrez-Martínez, I.; LunA-ReYes, L. F. "Understanding risks, benefits, and strategic alternatives of social media applications in the public sector". Government Information Quartely, n²9, p. 504-511, 2012.

PINA, V.; TORRES, L.; ROYO, S. "Are ICTs improving transparency and accountability in the EU regional and local governments? An empirical study". Public Administration, vol. 85, n 2, p. 449472, 2007.

Pinho, J. A. G.; SAcramento, A. "Accountability: já podemos traduzi-la para o português?". Revista de Administração Pública, vol. 43, nº 6, 2009.

PiotRowski, S. J. Governmental transparency in the path of administrative reform. Albany, New York: Suny Press, 2008.

Porumbescu, G. "Linking transparency to trust in government and voice". American Review of Public Administration, vol. 47, n 5, p. 520-537, 2017.

ROBERTS, A. Blacked out: government secrecy in the information age. New York: Cambridge University Press, 2006.

RUIJER, E., et al. "The politics of open government data: understanding organizational responses to pressure for more transparency". The American Review of Public Administration, vol. 50, $\mathrm{n}^{\circ} 3, \mathrm{p}$. 260-274, 2020.

SChlindWein, A. F. "Transparência digital no Poder Judiciário brasileiro: acesso à informação e controle social nos portais dos Tribunais de Justiça". Dissertação de Mestrado em Comunicação. Setor de Artes, Comunicação e Design, Universidade Federal do Paraná, Curitiba, 2019.

SCHUDSON, M. "The shortcomings of transparency for democracy". American Behavioral Scientist, p. $1-9,2020$.

Secom. Manual de orientação para atuação em mídias sociais: identidade-padrão de comunicação digital do Poder Executivo Federal. Brasília: Secom, 2014.

Silva, S. P. Transparência digital em instituições democráticas. In: MendonçA, R. F.; PereirA, M. A.; Filgueiras, F. (eds.). Democracia digital: publicidade, instituições e confronto político. Belo Horizonte: Editora da UFMG, p. 27-54, 2016.

SKALSKI, P. D., et al. Content analysis in the interactive Media Age. In: Neuendorf, K. A. (ed.). The content analysis guidebook. Los Angeles: Sage, p. 201-242, 2017.

SODRÉ, D. A. "A construção da imagem institucional da CGU no Facebook". Monografia em Comunicação Social. Universidade de Brasília, Brasília, 2014.

Stamati, T.; Papadopoulos, T.; Anagnostopoulos, D. "Social media for openness and accountability in the public sector: cases in the Greek context". Government Information Quarterly, vol. 32, $\mathrm{n}^{\circ} 1$, p. 12-29, 2015.

URbinati, N. "Crise e metamorfoses da democracia". Revista Brasileira de Ciências Sociais, vol. 28, n०82, p. 5-16, 2013.

Valle-Cruz, D., Sandoval-Almazan, R., Gil-Garcia, R. J. "Citizens' perceptions of the impact of information technology use on transparency, efficiency and corruption in local governments". Information Polity, vol. 21, n³, p. 321-334, 2016. 
Wood, T.; ARonczYk, M. "Publicity and transparency". American Behavioral Scientist, vol. 64, no 11, p. $1531-1544,2020$.

\section{Documento suplementar}

Tabela 1

Direcionamento dos links das postagens da CGU

\begin{tabular}{|l|c|c|c|}
\hline Direcionamento do link & Frequência & Porcentagem & Porcentagem válida \\
\hline Sites relacionados à CGU & 2.185 & 51,8 & 75,6 \\
\hline $\begin{array}{l}\text { Sites de governo não relacionados à } \\
\text { CGU }\end{array}$ & 370 & 8,6 & 12,8 \\
\hline Outros & 332 & 7,8 & 11,5 \\
\hline Link não identificável & 5 & 0,1 & 0,1 \\
\hline Total & $2.892^{37}$ & - & - \\
\hline $\begin{array}{l}\text { Ausentes (postagens que não } \\
\text { apresentam link) }\end{array}$ & 1337 & 31,7 & - \\
\hline Total & 4.212 & 100 & 100 \\
\hline
\end{tabular}

Fonte: Elaboração própria com base nas postagens da CGU.

Tabela 2

Cruzamento entre as variáveis "Tema da postagem" e "Presença de links"

\begin{tabular}{|c|c|c|c|c|}
\hline & & Presença de links & Ausência de links & Total \\
\hline \multirow{2}{*}{ Transparência } & $\mathrm{N}(\%)$ & $849(74,1)$ & $296(25,9)$ & $1.145(100)$ \\
\hline & $\mathrm{RP}$ & 2,4 & $-3,5$ & - \\
\hline \multirow{2}{*}{$\begin{array}{l}\text { Corrupção e demais } \\
\text { irregularidades }\end{array}$} & $\mathrm{N}(\%)$ & $686(66,5)$ & $346(33,5)$ & $1.032(100)$ \\
\hline & $\mathrm{RP}$ & $-0,7$ & 1,0 & - \\
\hline \multirow{2}{*}{ Participação } & $\mathrm{N}(\%)$ & $266(67,2)$ & $130(32,8)$ & $396(100)$ \\
\hline & $\mathrm{RP}$ & $-0,3$ & 0,4 & - \\
\hline \multirow{2}{*}{$\begin{array}{l}\text { Agenda e atribuições da } \\
\text { CGU }\end{array}$} & $\mathrm{N}(\%)$ & $265(70,7)$ & $110(29,3)$ & $375(100)$ \\
\hline & $\mathrm{RP}$ & 0,6 & $-0,8$ & - \\
\hline \multirow{2}{*}{ Cursos e concursos } & $\mathrm{N}(\%)$ & $270(85,7)$ & $45(14,3)$ & $315(100)$ \\
\hline & $\mathrm{RP}$ & 3,8 & $-5,5$ & - \\
\hline \multirow{2}{*}{ Gestão pública } & $\mathrm{N}(\%)$ & $258(86,6)$ & $40(13,4)$ & $298(100)$ \\
\hline & $\mathrm{RP}$ & 3,8 & $-5,6$ & - \\
\hline \multirow{2}{*}{ Pensamentos } & $\mathrm{N}(\%)$ & $10(4,3)$ & $220(95,7)$ & $230(100)$ \\
\hline & $\mathrm{RP}$ & $-11,7$ & 17,2 & - \\
\hline \multirow{2}{*}{$\begin{array}{l}\text { Feriados e datas } \\
\text { comemorativas }\end{array}$} & $\mathrm{N}(\%)$ & $112(67,5)$ & $54(32,5)$ & $166(100)$ \\
\hline & $\mathrm{RP}$ & $-0,1$ & 0,2 & - \\
\hline \multirow{2}{*}{ Outros } & $\mathrm{N}(\%)$ & $65(47,8)$ & $71(52,2)$ & $136(100)$ \\
\hline & $\mathrm{RP}$ & $-2,9$ & 4,2 & - \\
\hline \multirow{2}{*}{$\begin{array}{l}\text { Programas de civilidade } \\
\text { e ética }\end{array}$} & $\mathrm{N}(\%)$ & $94(79)$ & $25(21)$ & $119(100)$ \\
\hline & $\mathrm{RP}$ & 1,4 & $-2,1$ & - \\
\hline Total & $\mathrm{N}(\%)$ & $2.875(68,4)$ & $1.337(31,6)$ & $4.212(100)$ \\
\hline
\end{tabular}

Fonte: Elaboração própria com base nas postagens da CGU.

Resíduos padronizados significativos em destaque.

37 Dentre as 4.212 postagens analisadas, 2.875 apresentam links. Entretanto, existem 17 postagens que divulgam dois links cada. Sendo assim, a Tabela 1 apresenta a classificação de 2.892 . 
Tabela 3

Cruzamento entre as variáveis "Tema da postagem" e "Menção à Legislação"

\begin{tabular}{|c|c|c|c|c|}
\hline & & $\begin{array}{c}\text { Presença de } \\
\text { menção à } \\
\text { legislação }\end{array}$ & $\begin{array}{c}\text { Ausência de } \\
\text { menção à } \\
\text { legislação }\end{array}$ & Total \\
\hline \multirow{2}{*}{ Transparência } & $\mathrm{N}(\%)$ & $486(42,4)$ & $659(57,6)$ & $1.145(100)$ \\
\hline & RP & 15,7 & $-8,1$ & - \\
\hline \multirow{2}{*}{$\begin{array}{l}\text { Corrupção e demais } \\
\text { irregularidades }\end{array}$} & $\mathrm{N}(\%)$ & $107(10,4)$ & $925(89,6)$ & $1.032(100)$ \\
\hline & RP & $-7,6$ & 3,9 & - \\
\hline \multirow{2}{*}{ Participação } & $\mathrm{N}(\%)$ & $66(16,7)$ & $330(83,3)$ & $396(100)$ \\
\hline & RP & $-1,9$ & 1,0 & - \\
\hline \multirow{2}{*}{$\begin{array}{l}\text { Agenda e atribuições da } \\
\text { CGU }\end{array}$} & $\mathrm{N}(\%)$ & $64(17,1)$ & $311(82,9)$ & $375(100)$ \\
\hline & RP & $-1,7$ & 0,9 & - \\
\hline \multirow{2}{*}{ Cursos e concursos } & $\mathrm{N}(\%)$ & $82(26)$ & $233(74)$ & $315(100)$ \\
\hline & RP & 1,9 & $-1,0$ & - \\
\hline \multirow{2}{*}{ Gestão pública } & $\mathrm{N}(\%)$ & $52(17,4)$ & $246(82,6)$ & $298(100)$ \\
\hline & RP & $-1,4$ & 0,7 & - \\
\hline \multirow{2}{*}{ Pensamentos } & $\mathrm{N}(\%)$ & $2(0,9)$ & $228(99,1)$ & $230(100)$ \\
\hline & RP & $-6,7$ & 3,5 & - \\
\hline \multirow{2}{*}{$\begin{array}{l}\text { Feriados e datas } \\
\text { comemorativas }\end{array}$} & $\mathrm{N}(\%)$ & $13(7,8)$ & $153(92,2)$ & $166(100)$ \\
\hline & RP & $-3,7$ & 1,9 & - \\
\hline \multirow{2}{*}{ Outros } & $\mathrm{N}(\%)$ & $13(9,6)$ & $123(90,4)$ & $136(100)$ \\
\hline & RP & $-2,9$ & 1,5 & - \\
\hline \multirow{2}{*}{$\begin{array}{l}\text { Programas de civilidade } \\
\text { e ética }\end{array}$} & $\mathrm{N}(\%)$ & $5(4,2)$ & $114(95,8)$ & $119(100)$ \\
\hline & RP & $-4,0$ & 2,1 & - \\
\hline Total & $\mathrm{N}(\%)$ & $890(21,1)$ & $3.322(78,9)$ & $4.212(100)$ \\
\hline
\end{tabular}

Fonte: Elaboração própria com base nas postagens da CGU.

Resíduos padronizados significativos em destaque. 
Tabela 4

Cruzamento entre as variáveis "Tema da postagem"

e "Menção à personalidade ou autoridade"

\begin{tabular}{|c|c|c|c|c|}
\hline & & $\begin{array}{c}\text { Presença de } \\
\text { menção à } \\
\text { personalidade ou } \\
\text { autoridade }\end{array}$ & $\begin{array}{c}\text { Ausência de } \\
\text { menção à } \\
\text { personalidade ou } \\
\text { autoridade }\end{array}$ & Total \\
\hline \multirow{2}{*}{ Transparência } & $\mathrm{N}(\%)$ & $21(1,8)$ & $1.124(98,2)$ & $1.145(100)$ \\
\hline & $\mathrm{RP}$ & $-7,0$ & 2,0 & - \\
\hline \multirow{2}{*}{$\begin{array}{l}\text { Corrupção e demais } \\
\text { irregularidades }\end{array}$} & $\mathrm{N}(\%)$ & $74(7,2)$ & $958(92,8)$ & $1.032(100)$ \\
\hline & $\mathrm{RP}$ & $-0,4$ & 0,1 & - \\
\hline \multirow{2}{*}{ Participação } & $\mathrm{N}(\%)$ & $6(1,5)$ & $390(98,5)$ & $396(100)$ \\
\hline & $\mathrm{RP}$ & $-4,4$ & $-1,2$ & - \\
\hline \multirow{2}{*}{$\begin{array}{l}\text { Agenda e atribuições da } \\
\text { CGU }\end{array}$} & $\mathrm{N}(\%)$ & $80(21,3)$ & $295(78,7)$ & $375(100)$ \\
\hline & $\mathrm{RP}$ & 9,7 & $-2,8$ & - \\
\hline \multirow{2}{*}{ Cursos e concursos } & $\mathrm{N}(\%)$ & $1(0,3)$ & $314(99,7)$ & $315(100)$ \\
\hline & $\mathrm{RP}$ & $-4,7$ & $-1,3$ & - \\
\hline \multirow{2}{*}{ Gestão pública } & $\mathrm{N}(\%)$ & $10(3,4)$ & $288(96,6)$ & $298(100)$ \\
\hline & $\mathrm{RP}$ & $-2,6$ & 0,7 & - \\
\hline \multirow{2}{*}{ Pensamentos } & $\mathrm{N}(\%)$ & $71(30,9)$ & $159(69,1)$ & $230(100)$ \\
\hline & $\mathrm{RP}$ & 12,9 & $-3,7$ & - \\
\hline \multirow{2}{*}{$\begin{array}{l}\text { Feriados e datas } \\
\text { comemorativas }\end{array}$} & $\mathrm{N}(\%)$ & $32(19,3)$ & $134(80,7)$ & $166(100)$ \\
\hline & $\mathrm{RP}$ & 5,5 & $-1,6$ & - \\
\hline \multirow{2}{*}{ Outros } & $\mathrm{N}(\%)$ & $5(3,7)$ & $131(96,3)$ & $136(100)$ \\
\hline & $\mathrm{RP}$ & $-1,6$ & 0,5 & - \\
\hline \multirow{2}{*}{$\begin{array}{l}\text { Programas de civilidade } \\
\text { e ética }\end{array}$} & $\mathrm{N}(\%)$ & $17(14,3)$ & $102(85,7)$ & $119(100)$ \\
\hline & $\mathrm{RP}$ & 2,7 & $-0,8$ & - \\
\hline Total & $\mathrm{N}(\%)$ & $317(7,5)$ & $3.895(92,5)$ & $4.212(100)$ \\
\hline
\end{tabular}

Fonte: Elaboração própria com base nas postagens da CGU.

Resíduos padronizados significativos em desta 
Tabela 5

Cruzamento entre as variáveis "Tema da postagem"

e "Apelo ao envolvimento dos usuários"

\begin{tabular}{|c|c|c|c|c|}
\hline & & $\begin{array}{c}\text { Presença de apelo } \\
\text { ao envolvimento } \\
\text { dos usuários }\end{array}$ & $\begin{array}{c}\text { Ausência de apelo } \\
\text { ao envolvimento } \\
\text { dos usuários }\end{array}$ & Total \\
\hline \multirow{2}{*}{ Transparência } & $\mathrm{N}(\%)$ & $728(63,6)$ & $417(36,4)$ & $1.145(100)$ \\
\hline & RP & 0,6 & $-0,8$ & - \\
\hline \multirow{2}{*}{$\begin{array}{l}\text { Corrupção e demais } \\
\text { irregularidades }\end{array}$} & $\mathrm{N}(\%)$ & $657(63,7)$ & $375(36,3)$ & $1032(100)$ \\
\hline & $\mathrm{RP}$ & 0,6 & $-0,8$ & - \\
\hline \multirow{2}{*}{ Participação } & $\mathrm{N}(\%)$ & $284(71,7)$ & $112(28,3)$ & $396(100)$ \\
\hline & $\mathrm{RP}$ & 2,4 & $-3,1$ & - \\
\hline \multirow{2}{*}{$\begin{array}{l}\text { Agenda e atribuições da } \\
\text { CGU }\end{array}$} & $\mathrm{N}(\%)$ & $202(53,9)$ & $173(46,1)$ & $375(100)$ \\
\hline & RP & $-2,0$ & 2,6 & - \\
\hline \multirow{2}{*}{ Cursos e concursos } & $\mathrm{N}(\%)$ & $225(71,4)$ & $90(28,6)$ & $315(100)$ \\
\hline & $\mathrm{RP}$ & 2,1 & $-2,7$ & - \\
\hline \multirow{2}{*}{ Gestão pública } & $\mathrm{N}(\%)$ & $185(62,1)$ & $113(37,9)$ & $298(100)$ \\
\hline & $\mathrm{RP}$ & 0,0 & 0,0 & - \\
\hline \multirow{2}{*}{ Pensamentos } & $\mathrm{N}(\%)$ & $85(37)$ & $145(63)$ & $230(100)$ \\
\hline & RP & $-4,8$ & 6,2 & - \\
\hline \multirow{2}{*}{$\begin{array}{l}\text { Feriados e datas } \\
\text { comemorativas }\end{array}$} & $\mathrm{N}(\%)$ & $98(59)$ & $68(41)$ & $166(100)$ \\
\hline & $\mathrm{RP}$ & $-0,5$ & 0,6 & - \\
\hline \multirow{2}{*}{ Outros } & $\mathrm{N}(\%)$ & $63(46,3)$ & $73(53,7)$ & $136(100)$ \\
\hline & $\mathrm{RP}$ & $-2,3$ & 3,0 & - \\
\hline \multirow{2}{*}{$\begin{array}{l}\text { Programas de civilidade } \\
\text { e ética }\end{array}$} & $\mathrm{N}(\%)$ & $89(74,8)$ & $30(25,2)$ & $119(100)$ \\
\hline & $\mathrm{RP}$ & 1,8 & $-2,2$ & - \\
\hline Total & $\mathrm{N}(\%)$ & $2.616(62,1)$ & $1.596(37,9)$ & $4.212(100)$ \\
\hline
\end{tabular}

Fonte: Elaboração própria com base nas postagens da CGU

Resíduos padronizados significativos em destaque.

Tabela 6

Medidas de tendência central do engajamento aos tweets da CGU

\begin{tabular}{|l|c|c|c|}
\hline \multicolumn{1}{|c|}{ Tema da postagem } & Média & Mediana & Moda \\
\hline Pensamentos & 56,1 & 41 & $23^{*}$ \\
\hline Corrupção e demais irregularidades & 38,6 & 24 & $8^{*}$ \\
\hline Feriados e datas comemorativas & 37,3 & 22 & 10 \\
\hline Transparência & 26 & 19 & 9 \\
\hline Participação & 24,2 & 14 & 0 \\
\hline Gestão pública & 20,6 & 14 & 4 \\
\hline Cursos e concursos & 19,1 & 14 & 17 \\
\hline Programas de civilidade e ética & 15,6 & 13 & 5 \\
\hline Outros & 12,3 & 4 & 1 \\
\hline Agenda e atribuições da CGU & 10,4 & 7 & 7 \\
\hline
\end{tabular}

Fonte: Elaboração própria com base nas postagens da CGU.

* Há várias modas. O valor mostrado é o menor. 
Figura 1

Solicitação feita à CGU por meio da Lei de Acesso à Informação

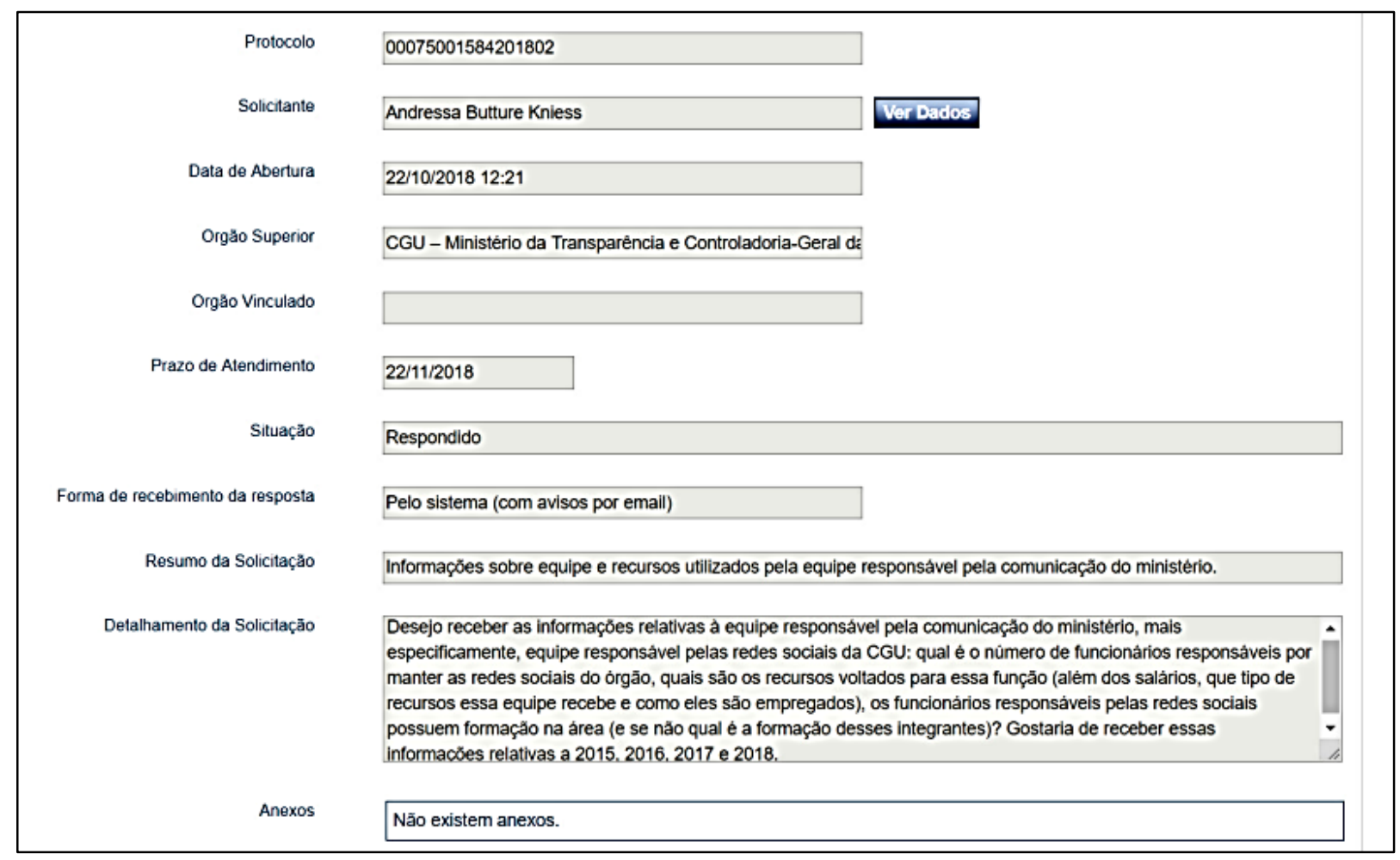

Fonte: Plataforma e-Sic, 2018

Figura 2

Resposta recebida da CGU

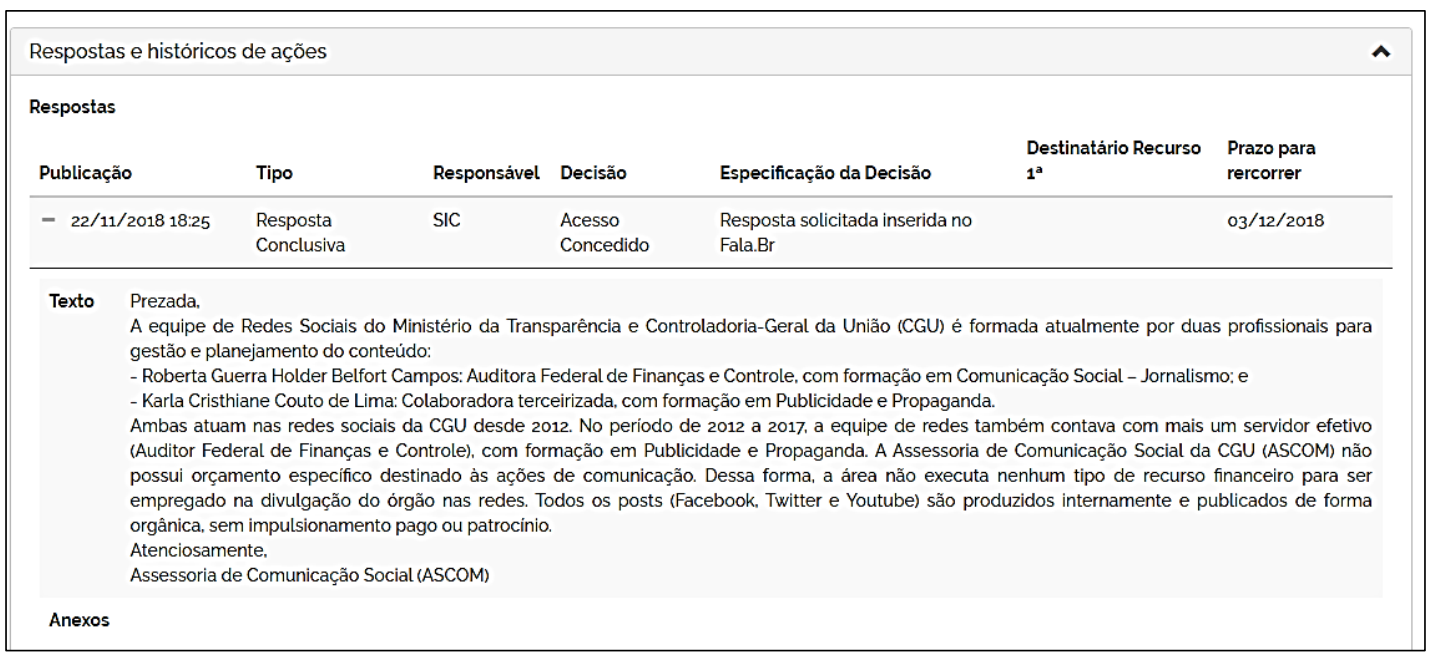

Fonte: Plataforma e-Sic, 2018. 


\begin{abstract}
How does the oversight institution use online communication? The idea of public transparency on the social networks of the Office of the Comptroller General

The article investigates whether and how the Office of the Comptroller General (CGU) addresses the idea of transparency in its social network profiles. Three questions guide our analysis: How is the idea of public transparency mobilized by the CGU on Facebook and Twitter? Since Facebook and Twitter have different structures and users, which communication strategies are privileged in each network? To what extent have CGU's digital communication routines been transformed in the transition between the Rousseff and Temer governments? The Content Analysis of 4,212 publications on Facebook and Twitter in 2015 and 2016 revealed that the institution favors two issues: transparency and corruption. Furthermore, public authorities are rarely mentioned, moving away from a personalist perspective of instrumentalizing communication. We also found out that government transition influenced the CGU's publishing routines.
\end{abstract}

Keywords: political communication; social networking sites; transparency; public communication; Brazilian office of the comptroller general

\title{
Resumen
}

¿Cómo utiliza el agente de inspección la comunicación en línea? La idea de transparencia pública en las redes sociales de la Contraloría General de la Federación

El artículo investiga si la Contraloría General de la Federación (CGU) aborda la idea de transparencia en sus perfiles de redes sociales y de qué manera. Tres preguntas guían el análisis: ¿Cómo moviliza CGU el tema de la transparencia pública en Facebook y Twitter? Dado que Facebook y Twitter tienen estructuras y usuarios diferentes, ¿qué estrategias de comunicación son privilegiadas en cada red? ¿En qué medida se han transformado las rutinas de comunicación digital de CGU en la transición entre los gobiernos de Rousseff y Temer? El Análisis de Contenido de 4.212 publicaciones en Facebook y Twitter en 2015 y 2016 reveló que la institución favorece dos temas: transparencia y corrupción. Además, las autoridades públicas rara vez se mencionan, alejándose de una perspectiva personalista de instrumentalización de la comunicación. También se descubrió que la transición del gobierno interfirió efectivamente con las rutinas de publicación de la entidad.

Palabras clave: comunicación política; redes sociales digitales; transparencia; comunicación publica; contralor general de la unión

\section{Résumé}

Comment l'agent d'inspection utilise-t-il la communication en ligne? L'idée de transparence publique dans les réseaux sociaux du Contrôleur Général Fédéral

L'article examine si, et de quelle manière, le Contrôleur Général Fédéral (CGU) aborde l'idée de transparence dans ses profils de réseaux sociaux. Trois questions guident l'analyse: comment le thème de la transparence publique est-il mobilisé par CGU sur Facebook et Twitter? Puisque Facebook et Twitter ont des structures et des utilisateurs différents, quelles stratégies de communication sont privilégiées dans chaque réseau? Dans quelle mesure les routines de communication numérique de CGU ont-elles été transformées lors de la transition entre les gouvernements Rousseff et Temer? L'analyse de contenu de 4212 publications sur Facebook et Twitter en 2015 et 2016 a révélé que l'institution privilégie deux thèmes: la transparence et la corruption. De plus, les pouvoirs publics sont rarement mentionnés, s'éloignant d'une perspective personnaliste d'instrumentalisation de la communication. Il a également été découvert que la transition gouvernementale interférait effectivement avec les routines de publication de l'entité.

Mots-clés: communication politique; réseaux sociaux numériques; transparence; communication publique; contrôleur général du Brésil

Artigo submetido à publicação em 24 de novembro de 2019. Versão final aprovada em 7 de janeiro de 2021.

Opinião Pública adota a licença Creative Commons CC-BY.

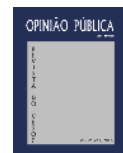

